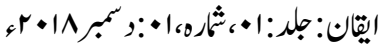

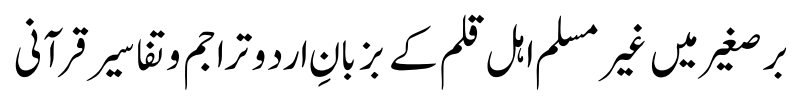

\title{
Urdu Quranic Translations \& Interpretations by Non-Muslims in Sub-Continent
}

\section{Dr. Sajid Asdullah}

Associate Professor, Department of Islamic Studies, Govt. Postgraduate College, Samanabad, Faisalabad.

\begin{abstract}
Islamic literary legacy is diverse and multidimensional in Subcontinent despite its being prone to religious $b$ and the issue of migration integral part of Islamic literary legacy is the Quranic translations $\mathcal{E}$ interpretations. The main aspect of these translations $\mathcal{E}$ interpretations are the endeavors put forward by Muslim as well as non-Muslim scholars. Keeping in view the endeavors translations $\mathcal{E}$ interpretations of Quran, the nonMuslims minorities of sub-continent can be divided into two groups. The first group of part is based on the followers of Judaism, Parsee, Buddhist, Sikhism, Jainism and idols of Kalash whose translations and interpretations is not well known. Whereas, the second group endure Christians, Hindus and Qadyanis. Christians and Hidus consider Quran as non-revealed. Since the style of their interpretations is based on criticism and rejection in aggressive manner. Whereas the interpretations by Qadyanis are focused on religious polarized beliefs and ideologies taking into considerations Quran as revealed. That's why Qadyanis interpretations are not accepted in Muslim community. The criticism by non-Muslims writers has resulted in rational approach for study of Quran instead of tendency based on esteem among Muslim. This paper represents aforementioned non-Muslims services regarding Quranic Interpretations and Translations which are distinguished in Muslims Interpreters.
\end{abstract}

Keywords: Quran, Interpretations, Translations, Non-Muslims, sub-continent, Hidus, Qadyanis. 


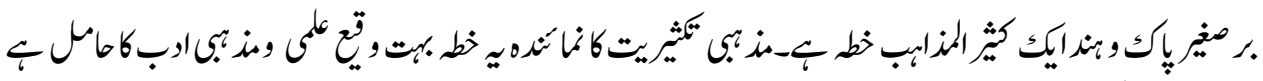

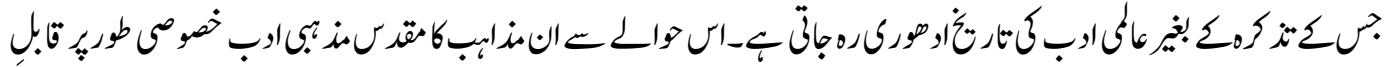

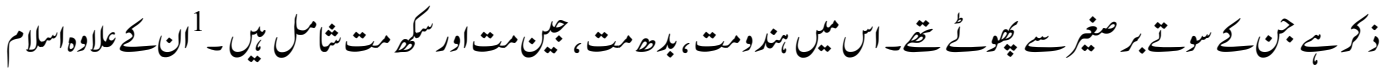

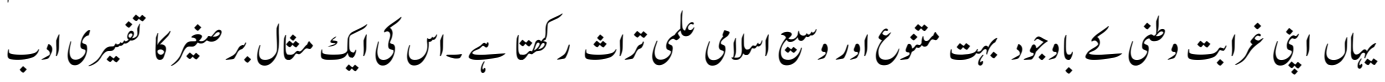

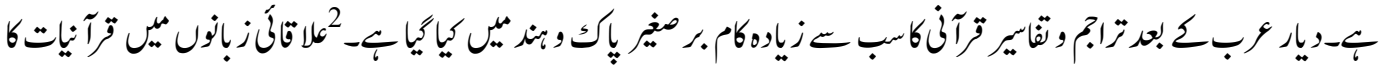

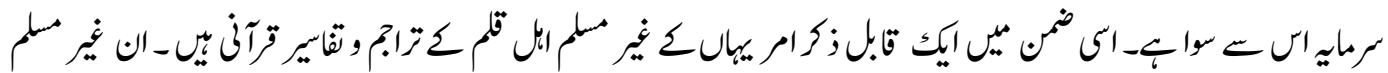

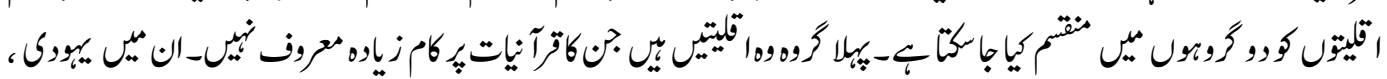

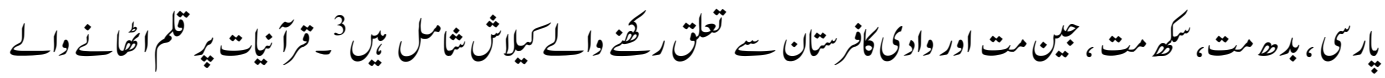

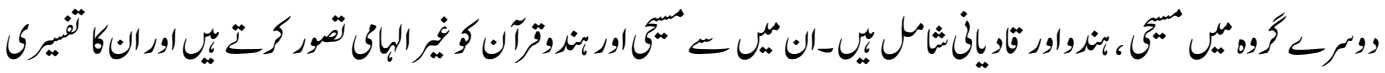

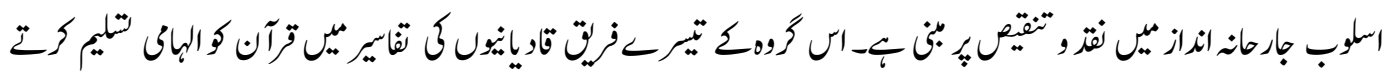

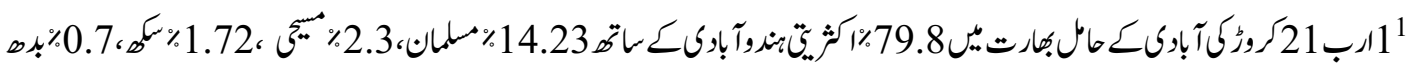

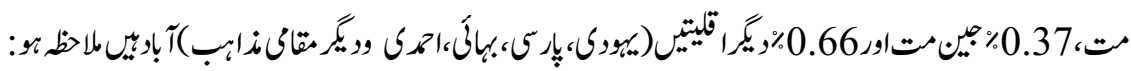
https://www.census2011.co.in/religion.php

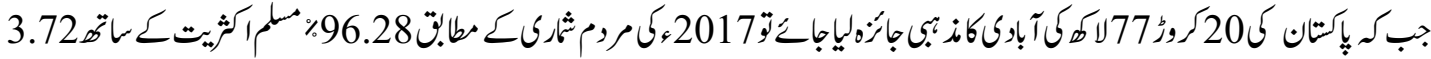

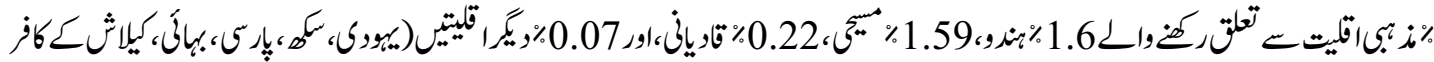

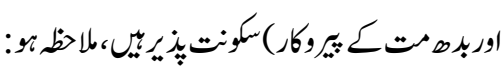
http://www.pbs.gov.pk/sites/default/files//tables/POPULATION\%20BY\%20RELIGION.pdf : 9 :

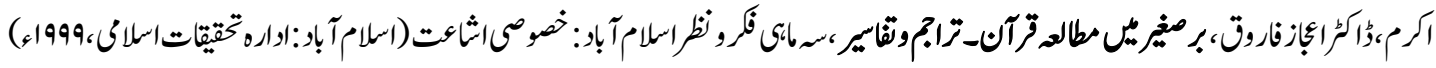
94-94: 0

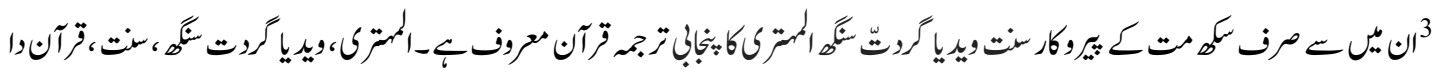

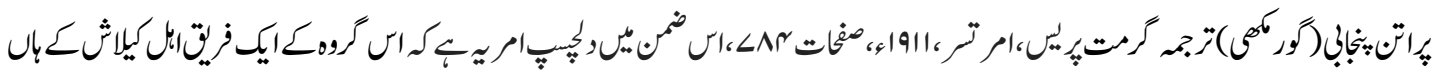

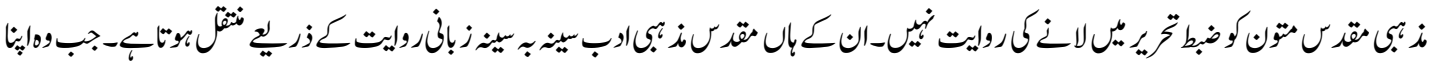

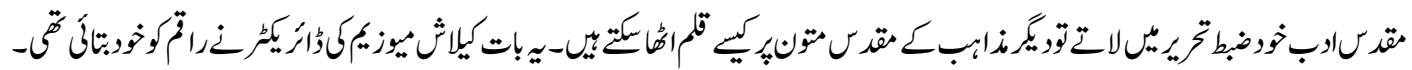




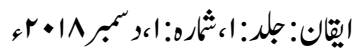

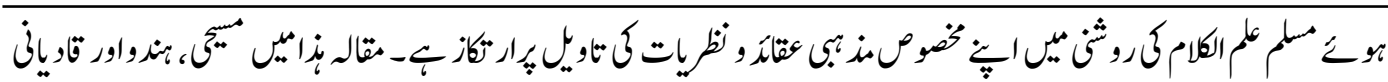

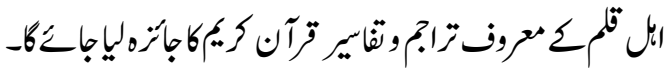

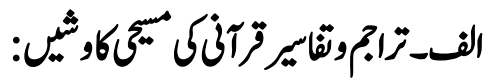

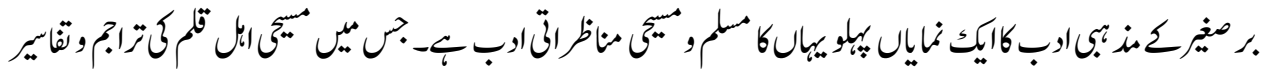

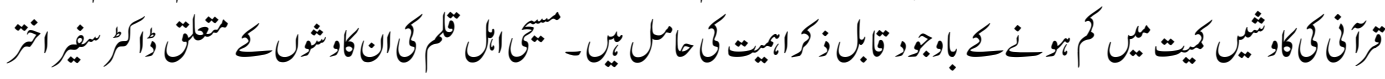

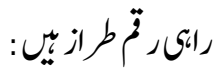

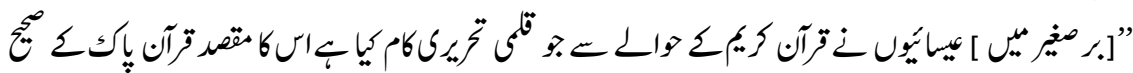

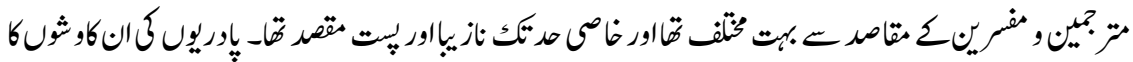

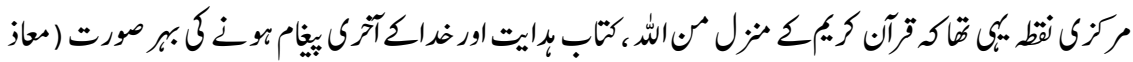

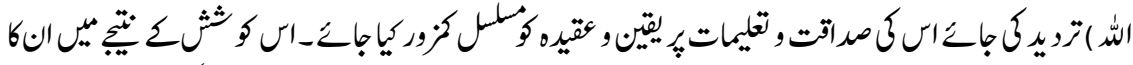

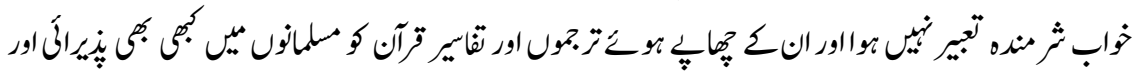

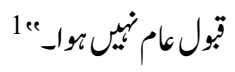

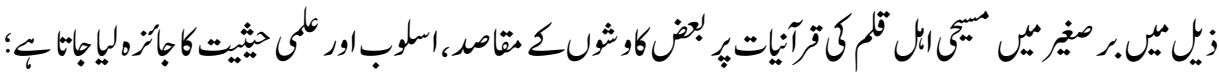

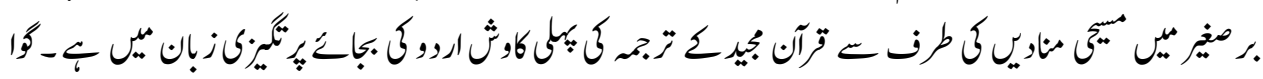

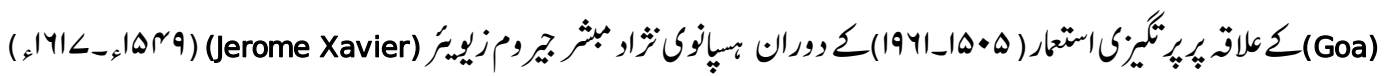

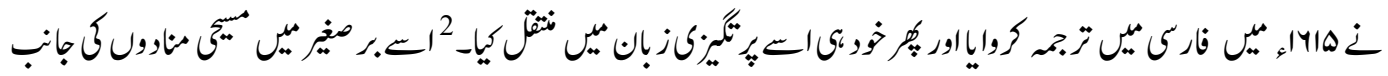

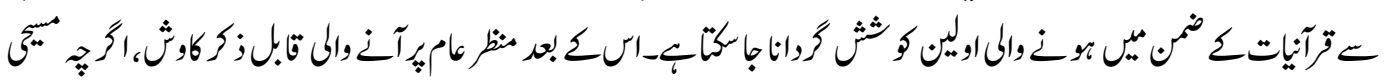

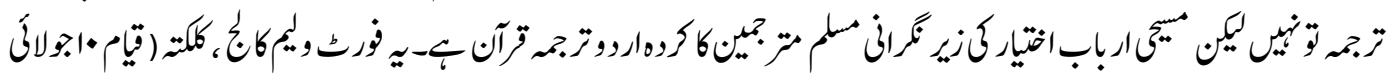
3 (1A...

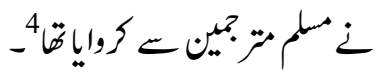

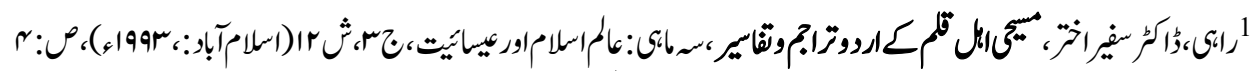

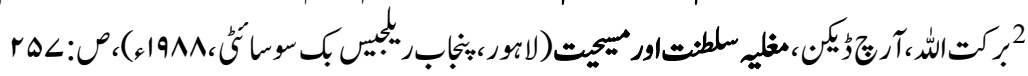

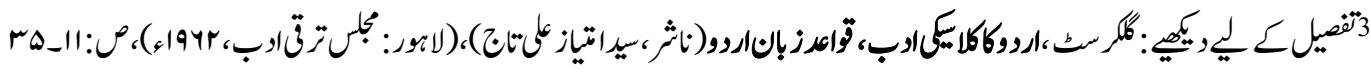

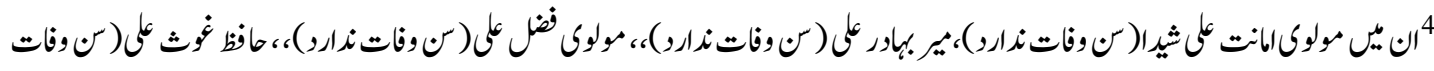

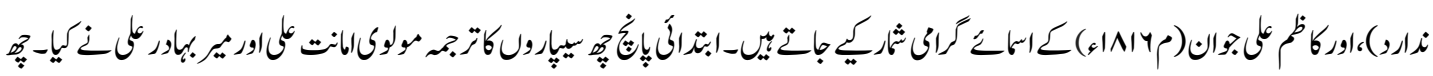




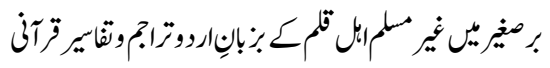

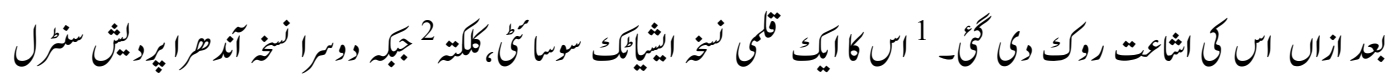

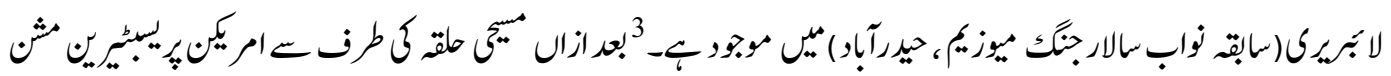

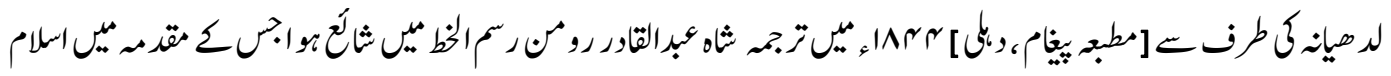

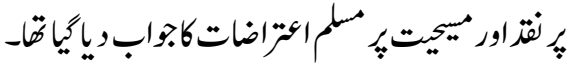

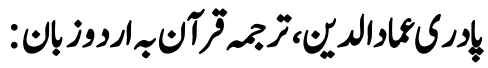

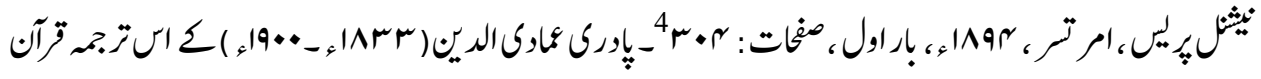

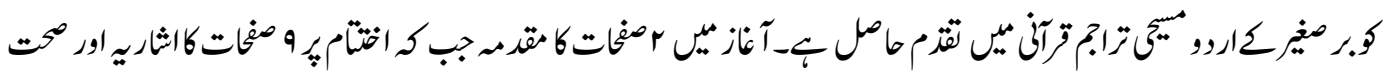

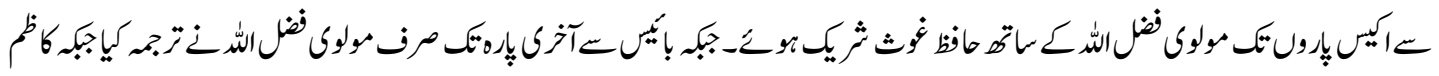

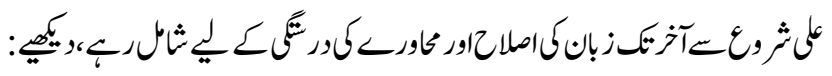

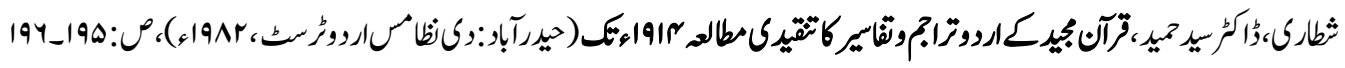

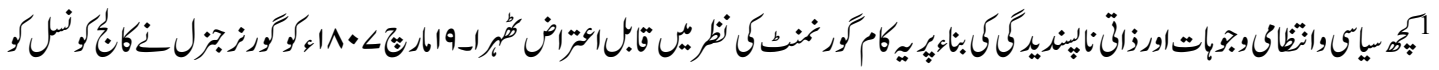

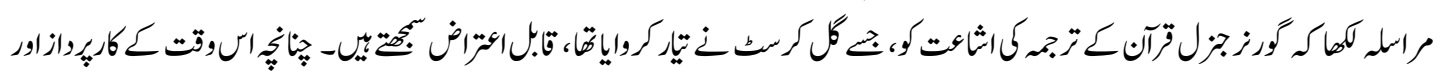

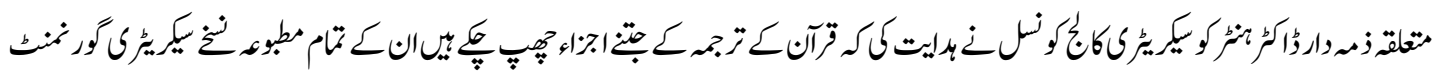

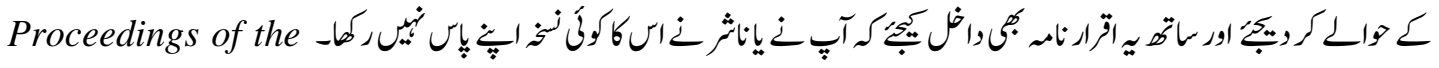

College of Fort William (1801-1807), p:298.

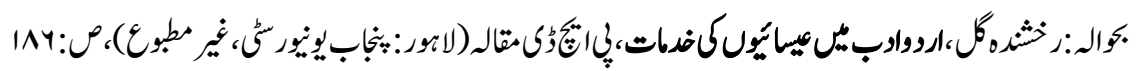

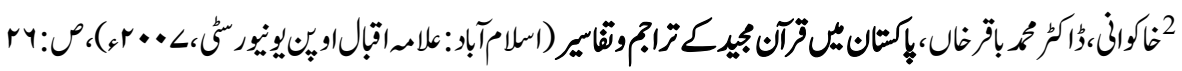

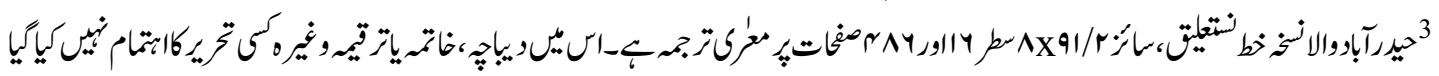

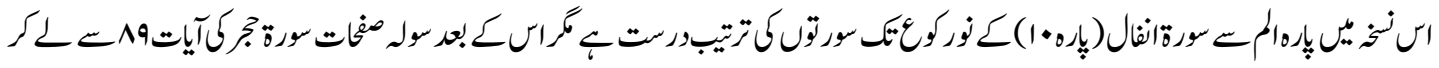

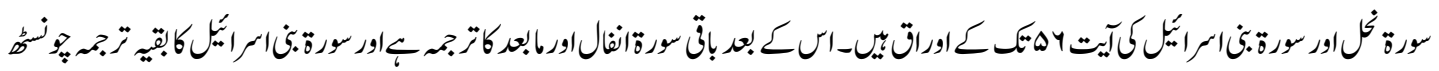

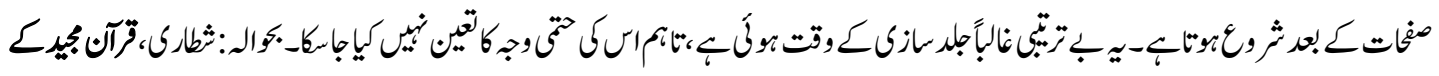

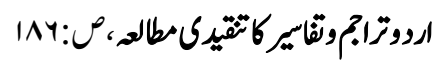

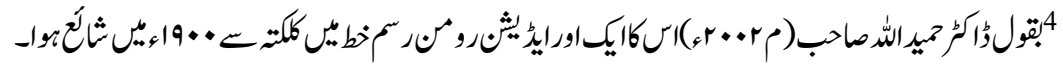

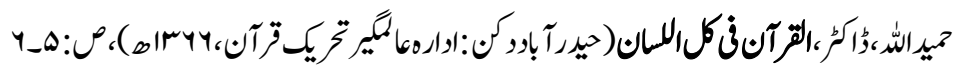




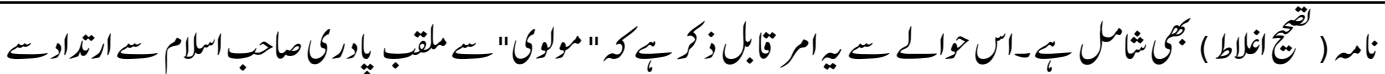

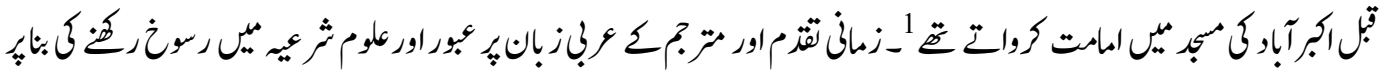

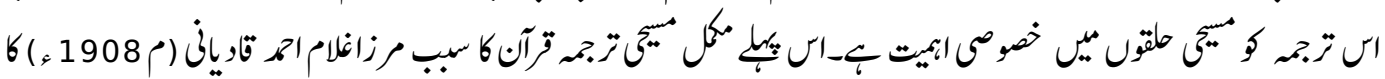

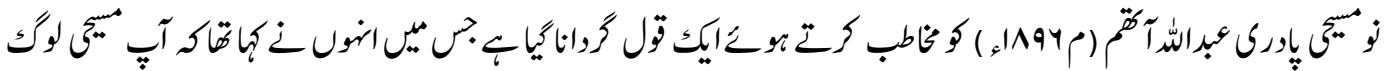

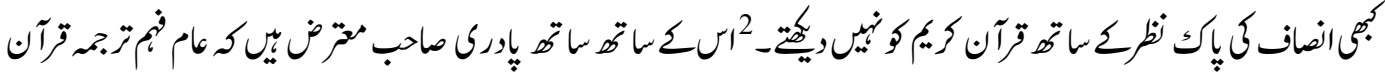

$$
\text { رستياب نهي }{ }^{3}
$$

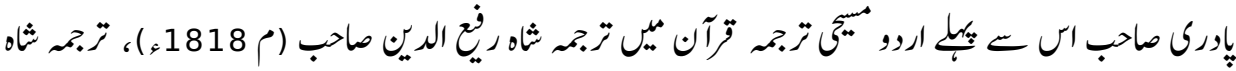

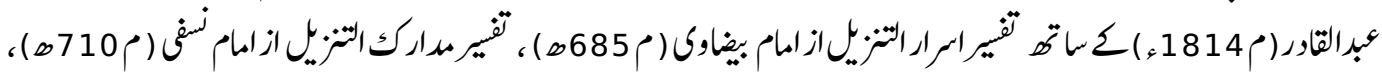

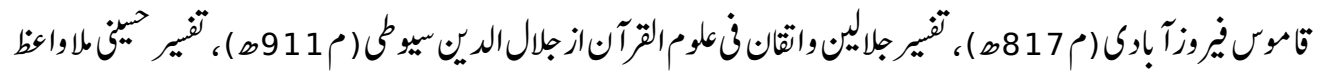

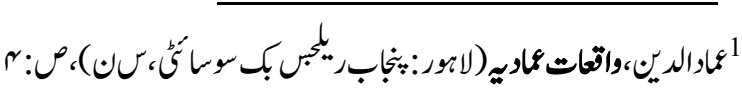

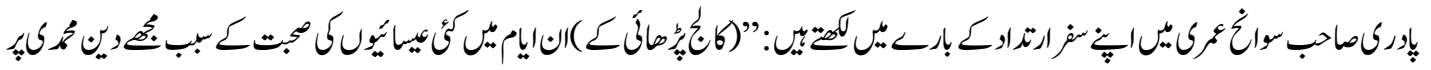

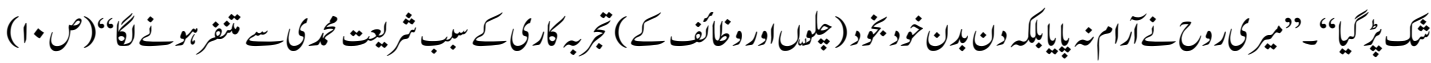

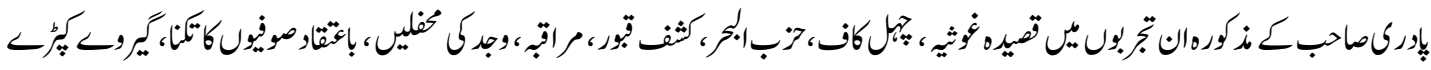

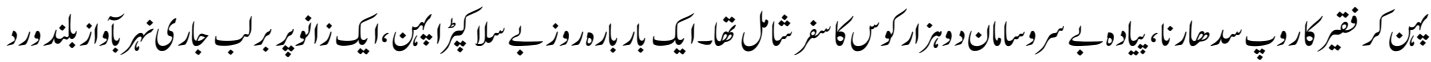

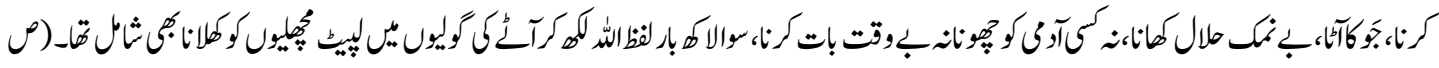

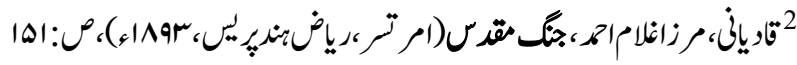

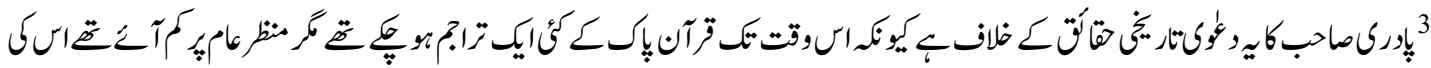

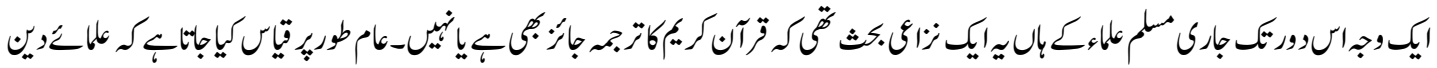

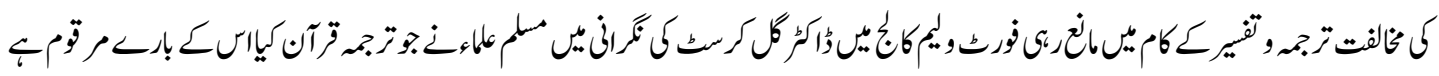

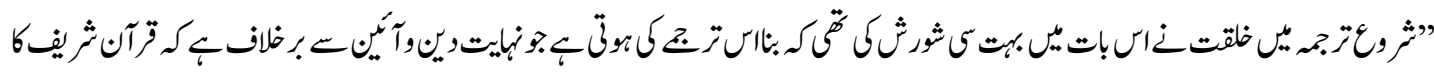

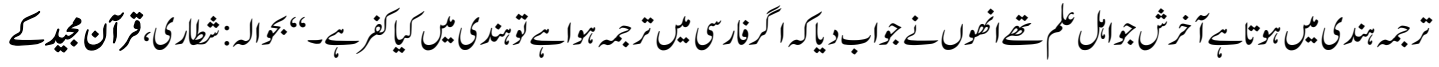




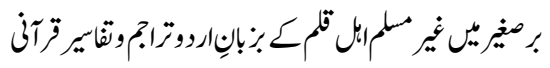

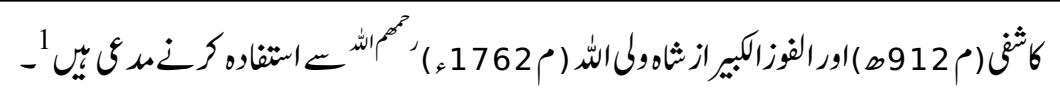

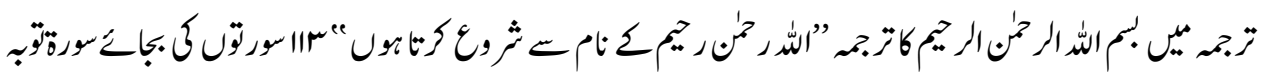

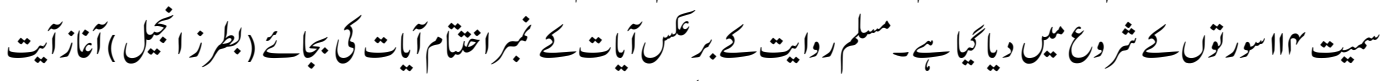

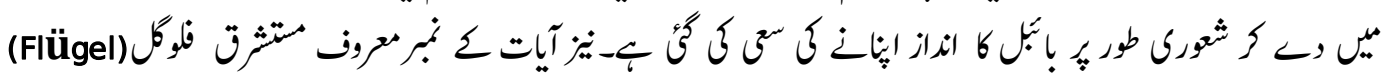

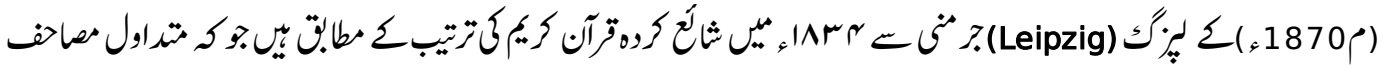

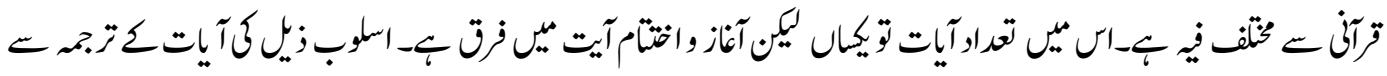

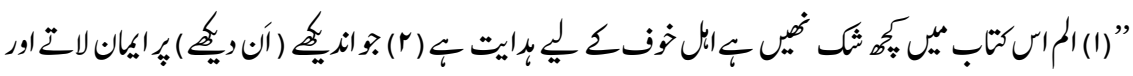

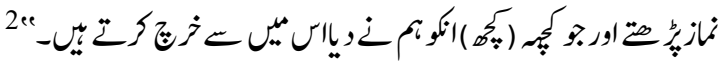

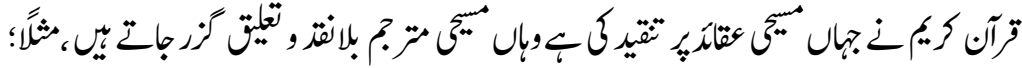

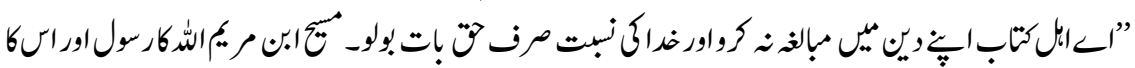

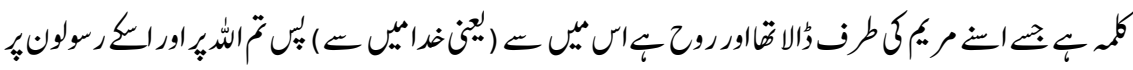

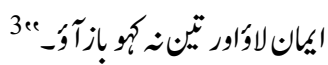

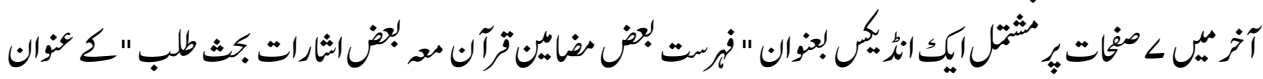

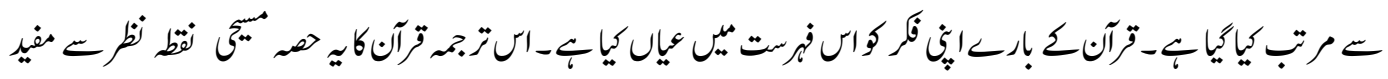

$$
-4
$$

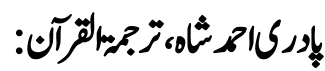

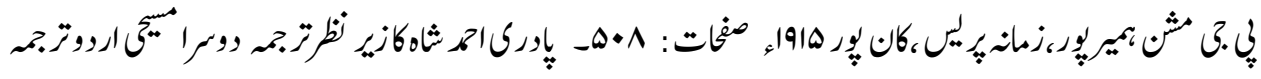

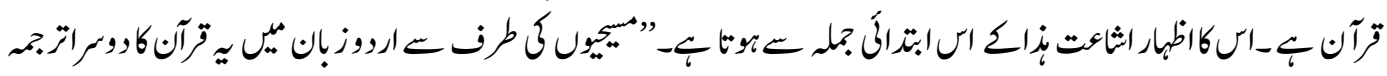

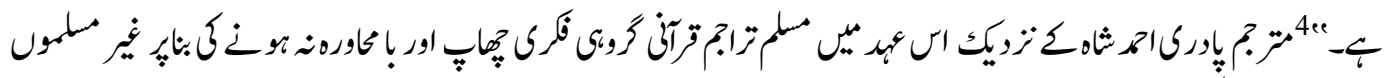

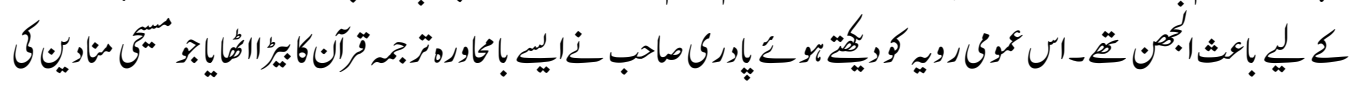

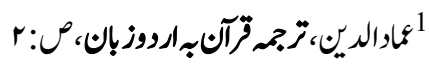

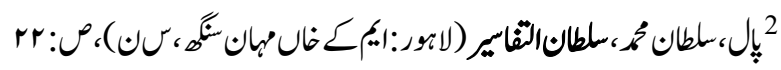

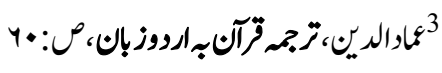

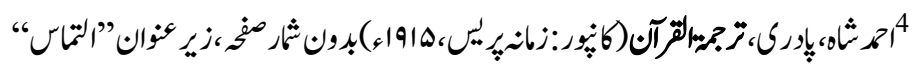




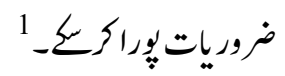

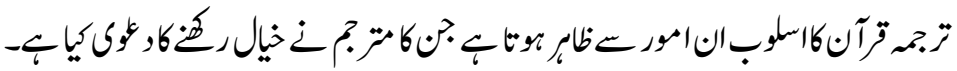

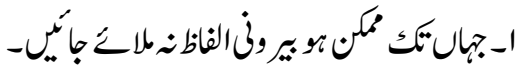

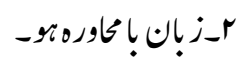

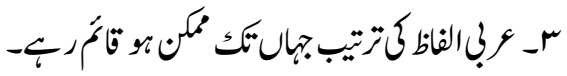

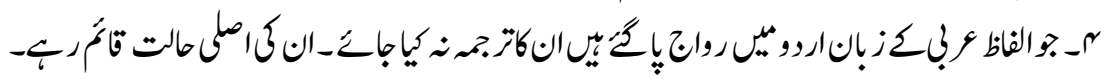

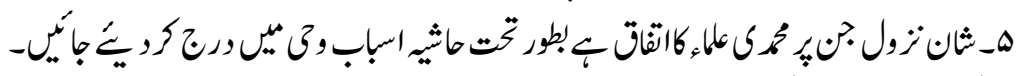

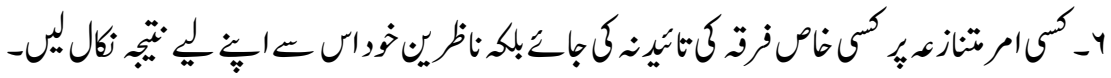

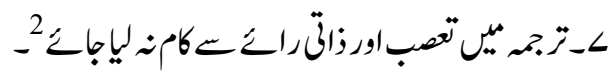

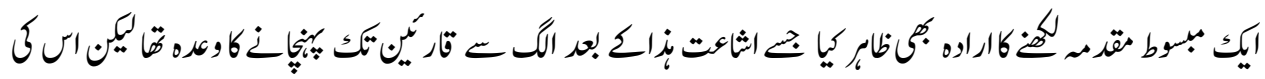

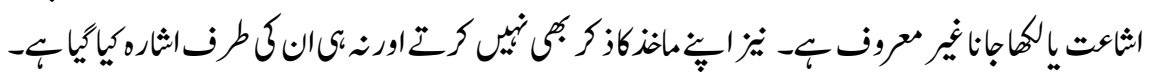

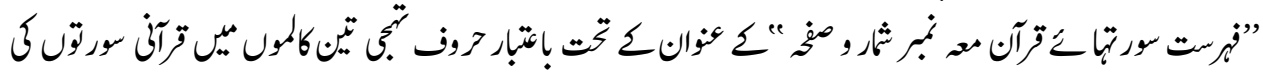

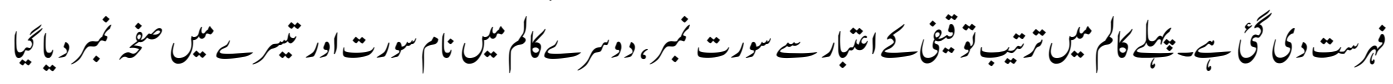

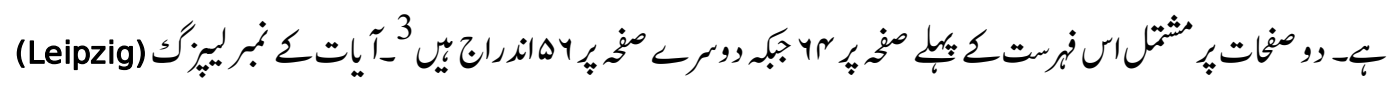

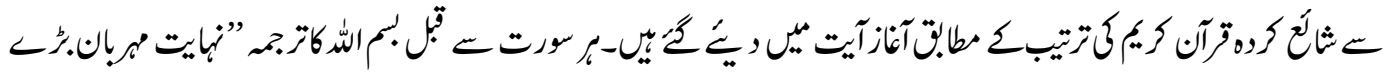

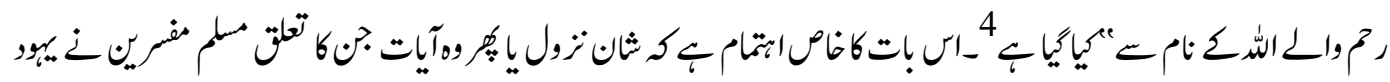

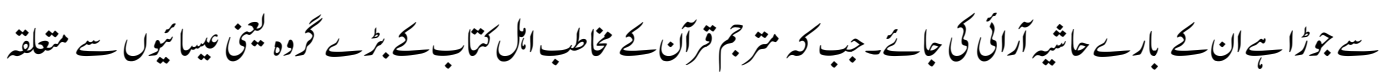

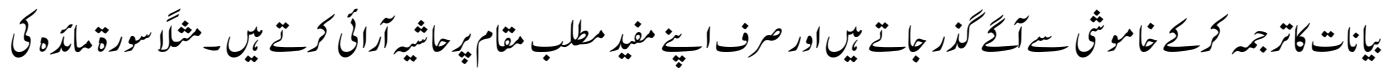

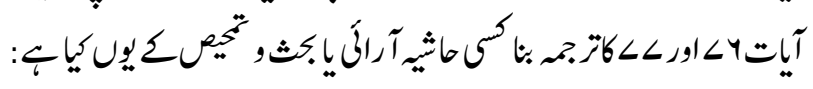

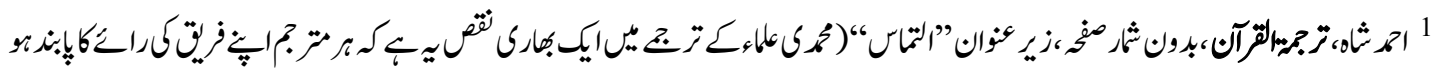

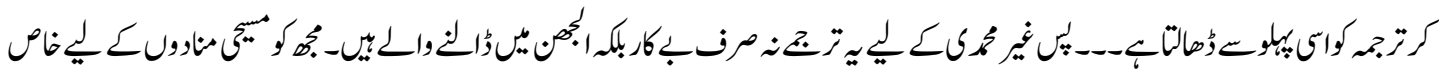

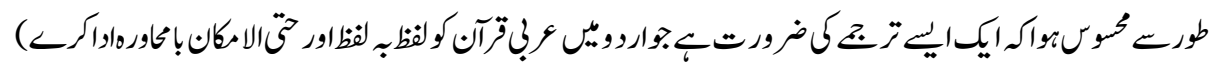

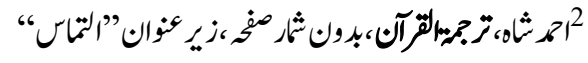




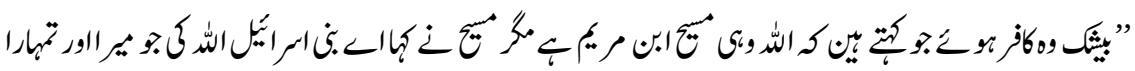

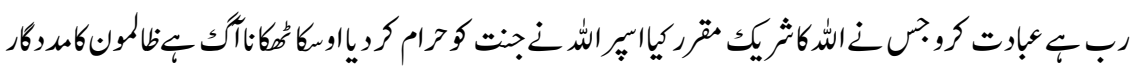

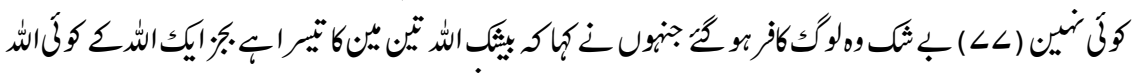

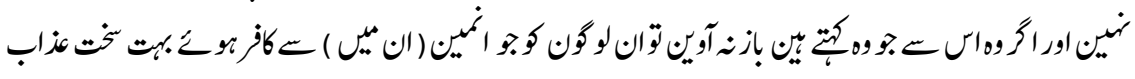

1 1"c-6\%

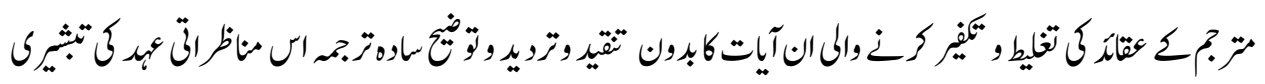

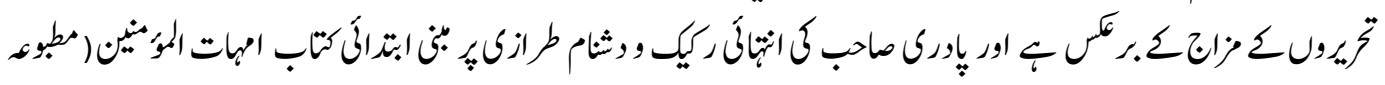

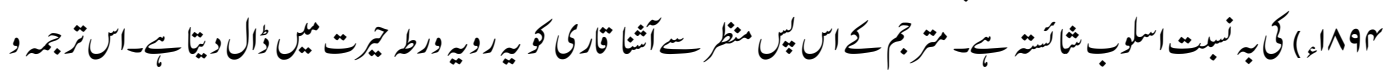

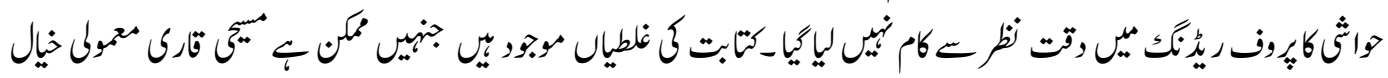

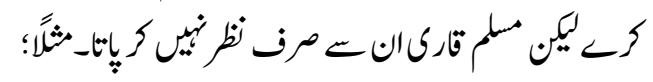

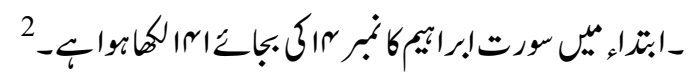

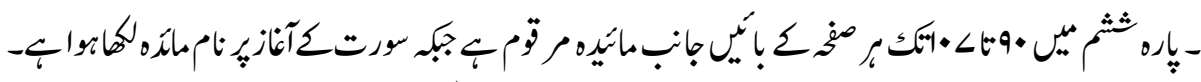

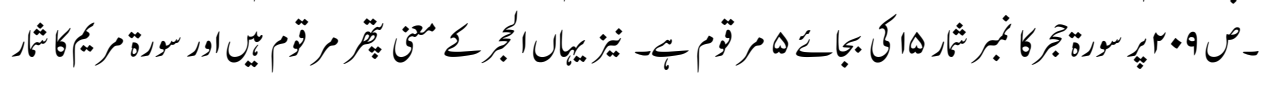

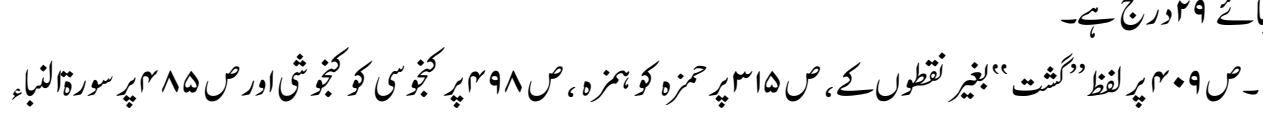

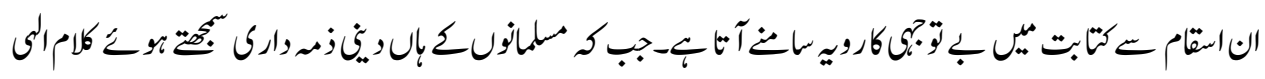
كوبورهبالمابع

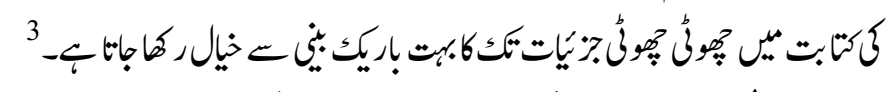

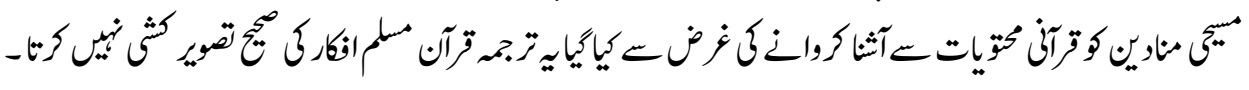

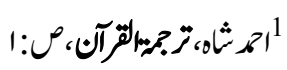

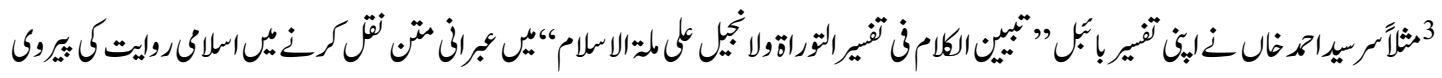

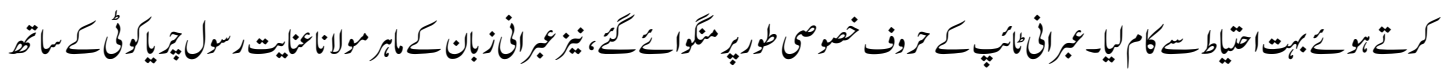

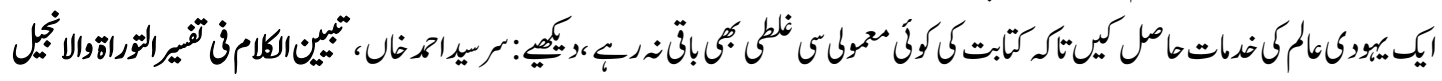

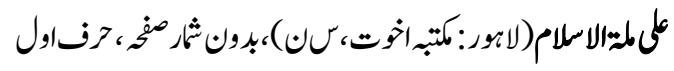




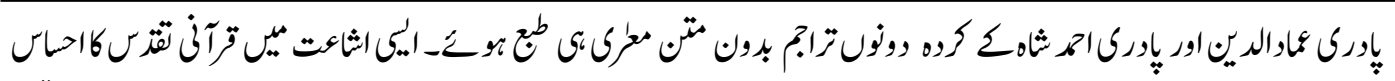

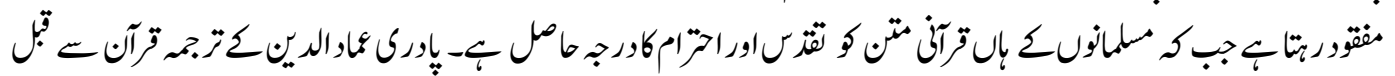

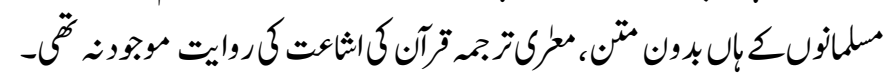

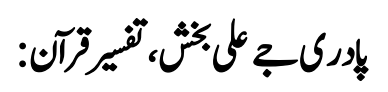

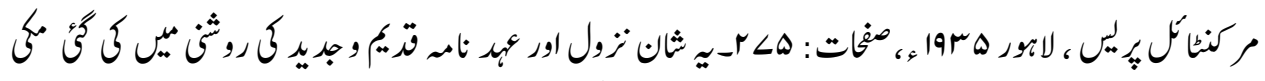

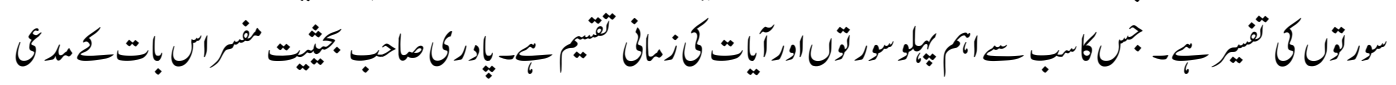

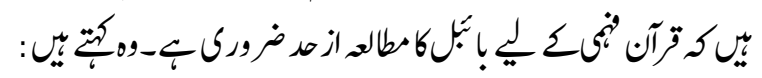

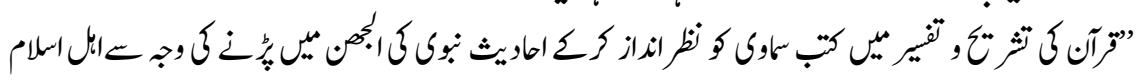

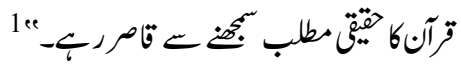

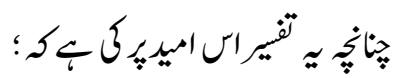

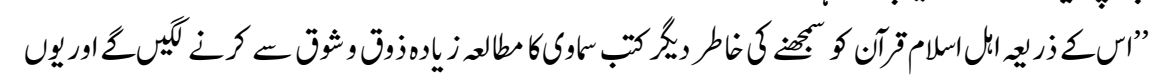

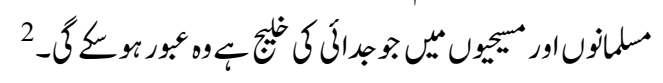

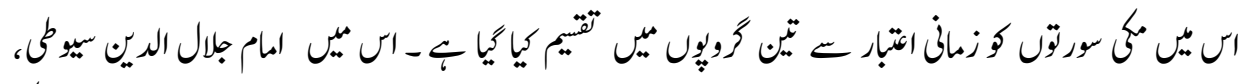

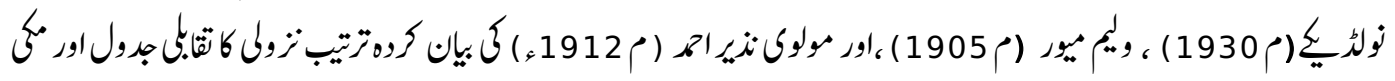

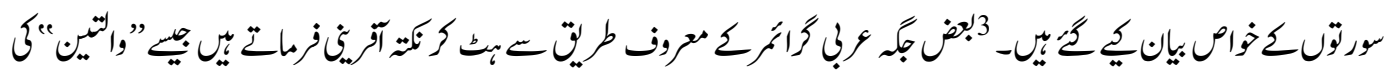

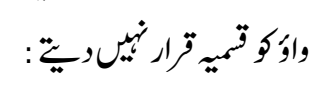

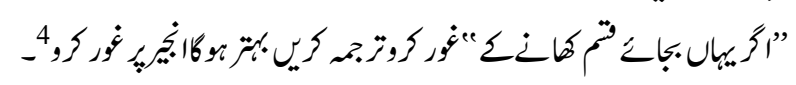

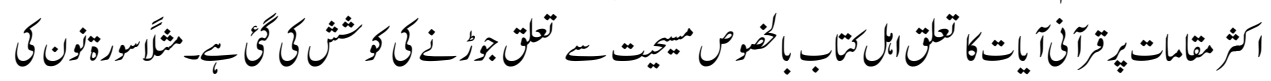

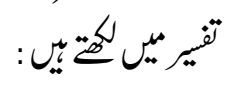

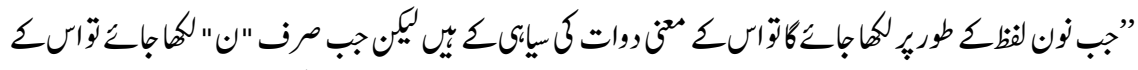

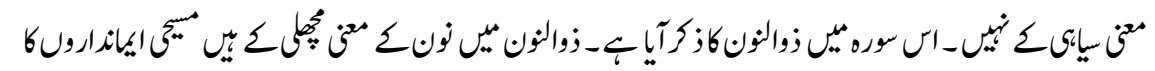

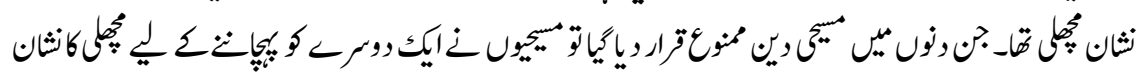

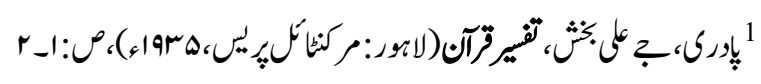




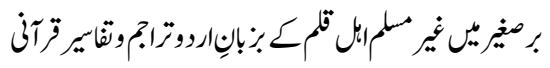

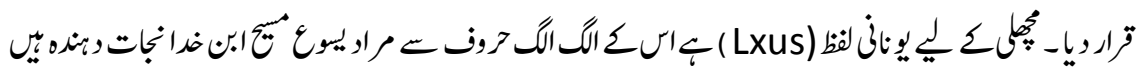

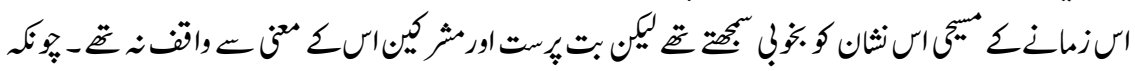

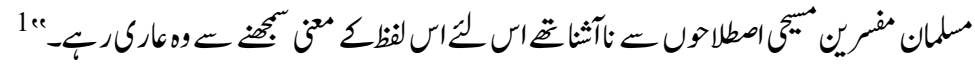

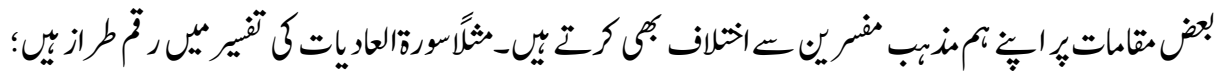

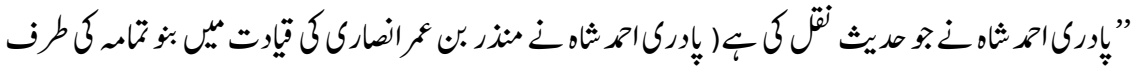

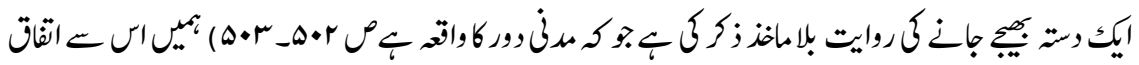

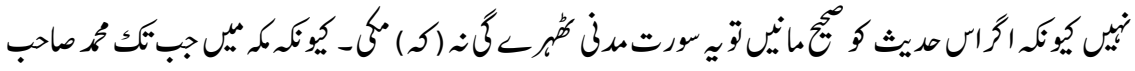

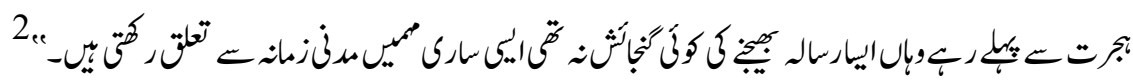

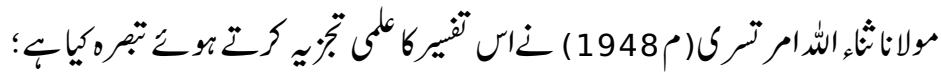

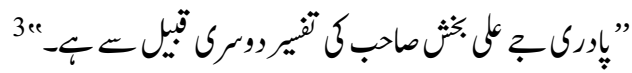

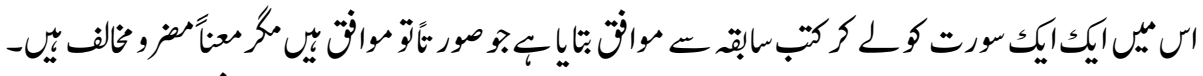

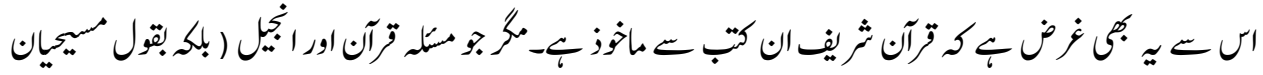

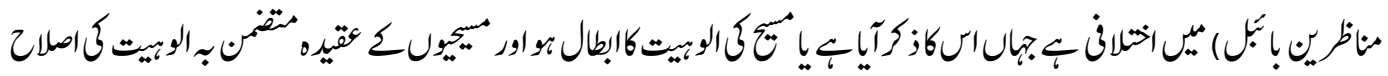

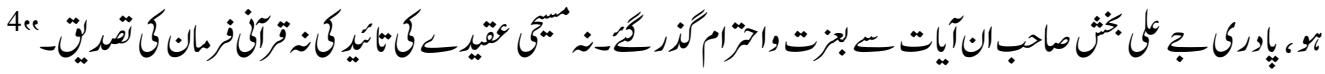

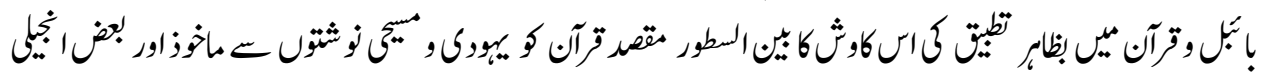

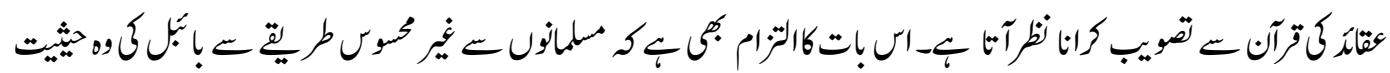

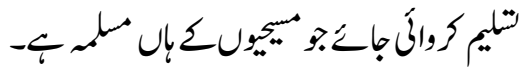

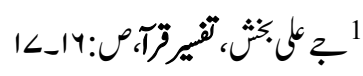
ه

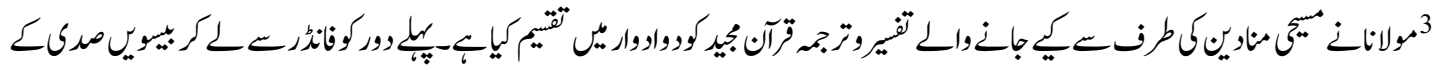

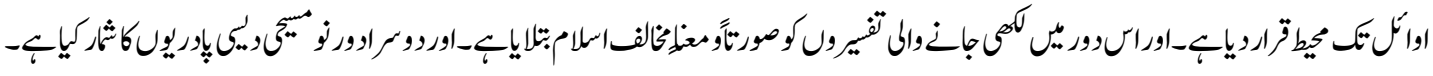

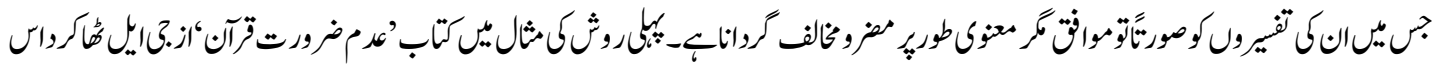

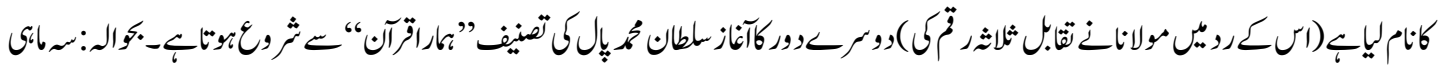

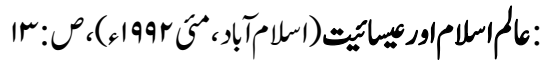

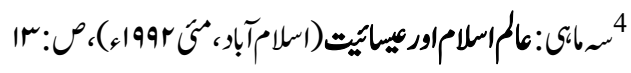




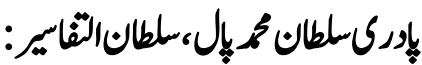

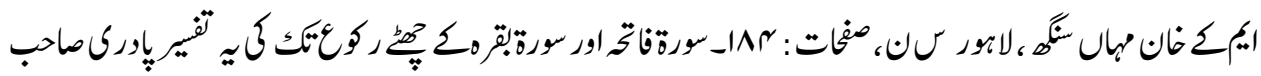

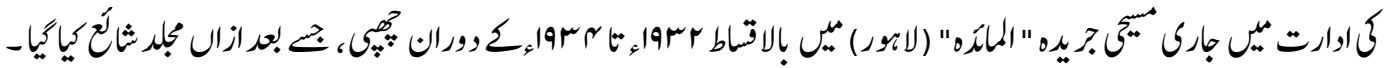

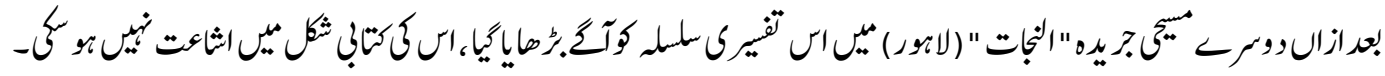

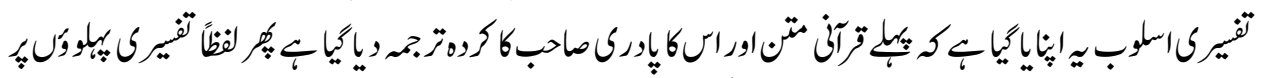

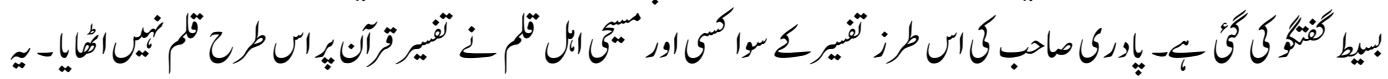

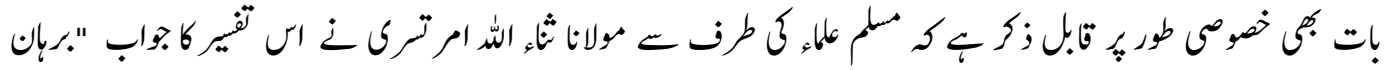

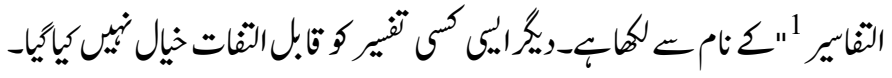

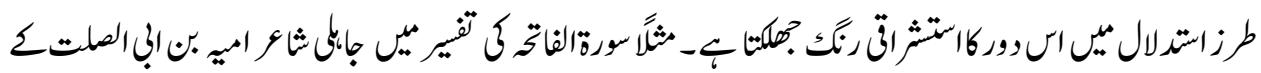

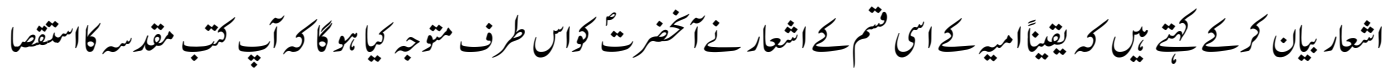

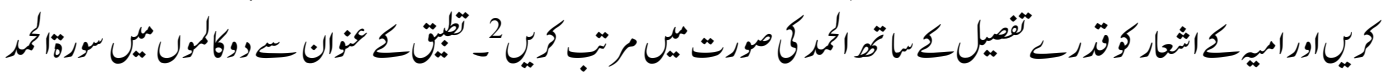

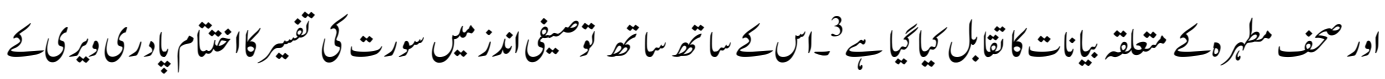

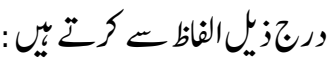

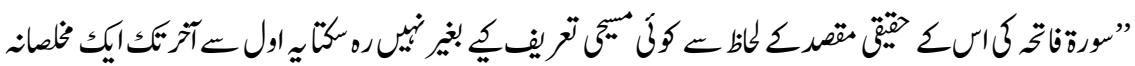

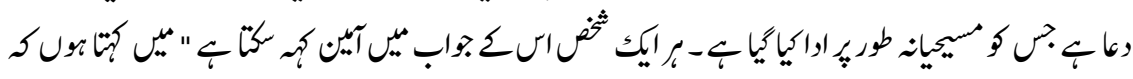

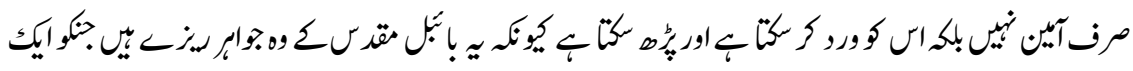

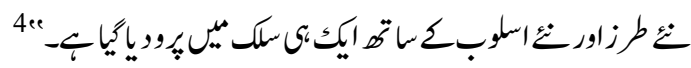

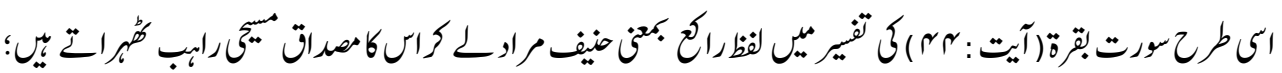

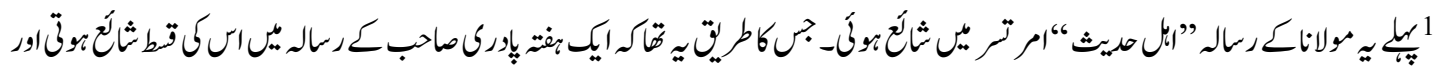

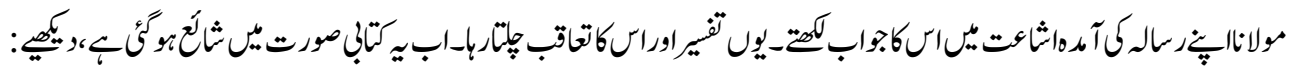

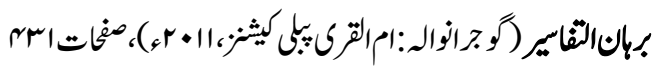

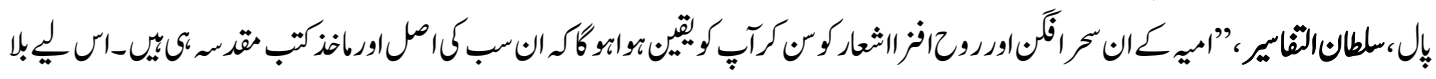

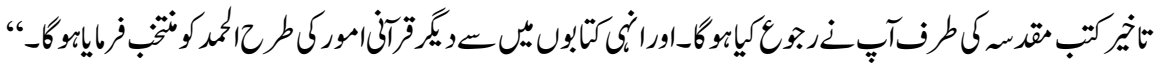

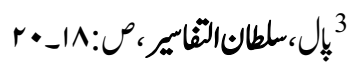

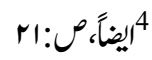




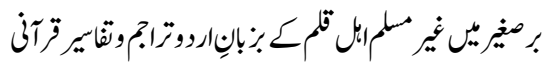

"

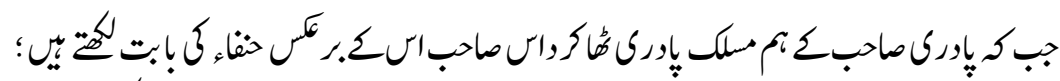

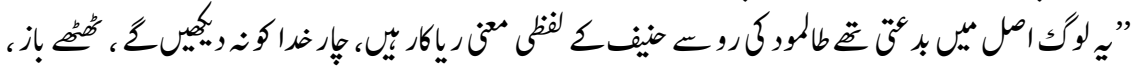

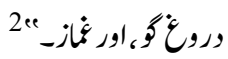

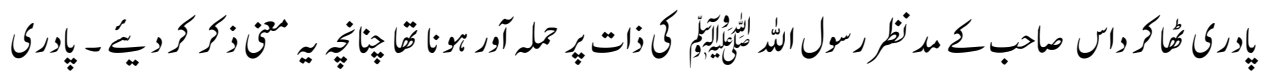

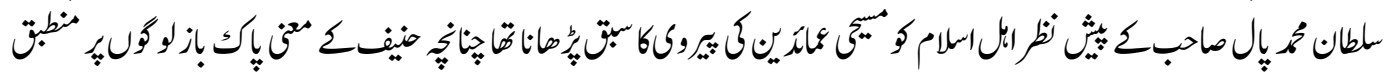

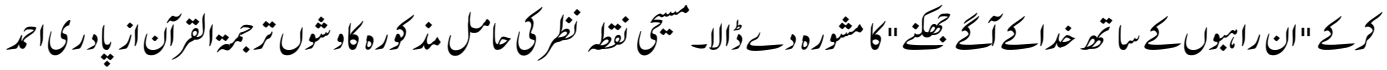

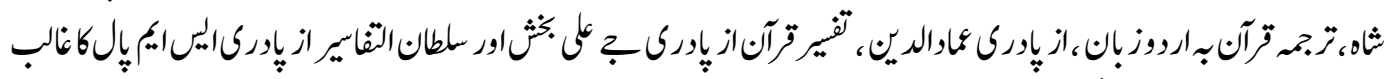

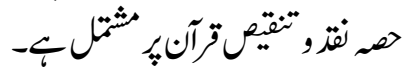

\section{موردظاتح:}

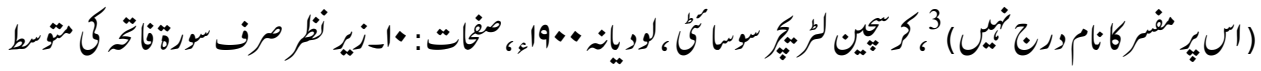

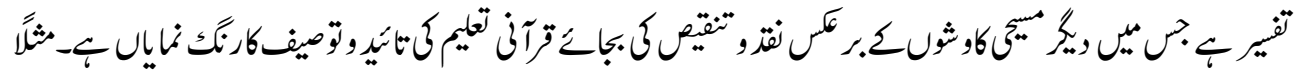

"

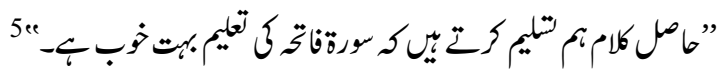

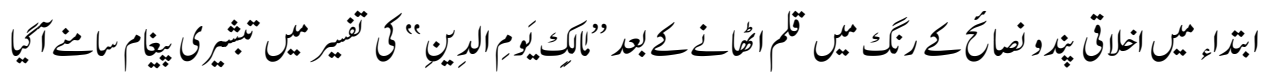

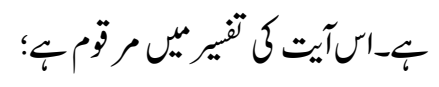

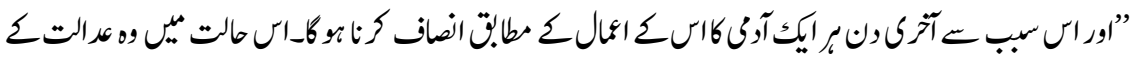

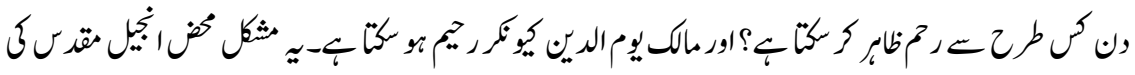

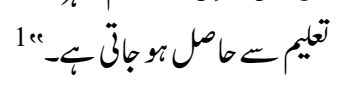

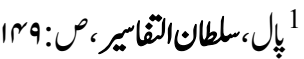

ra

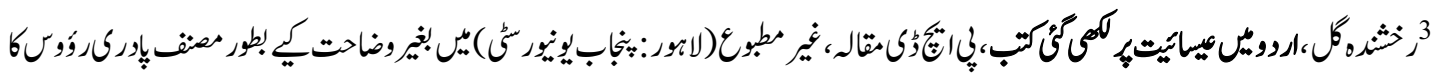
证

r

ه:: 0 


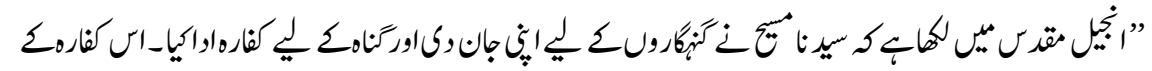

$$
\text { "2" }
$$

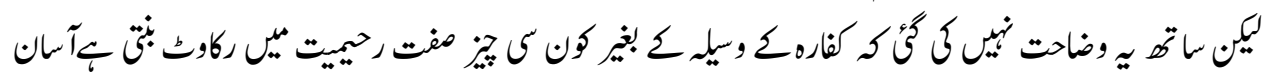

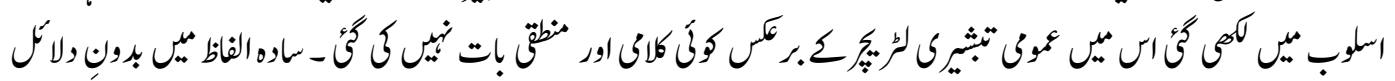

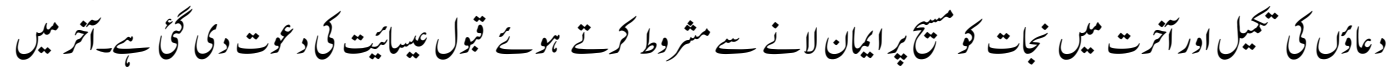

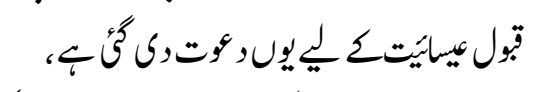

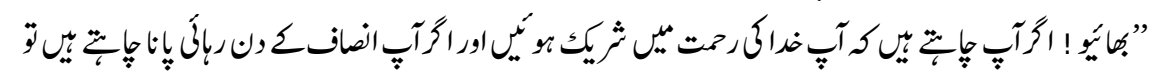

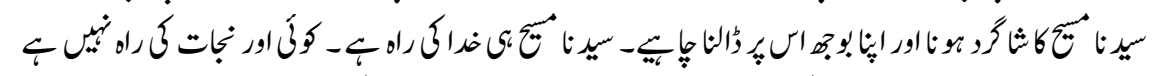

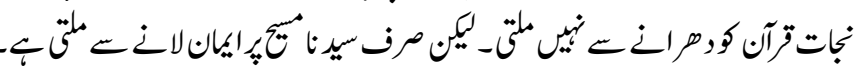

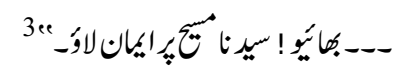

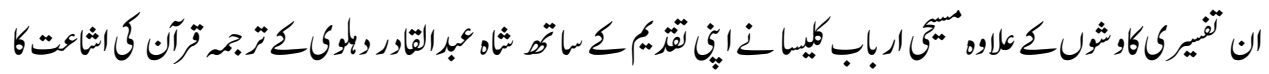

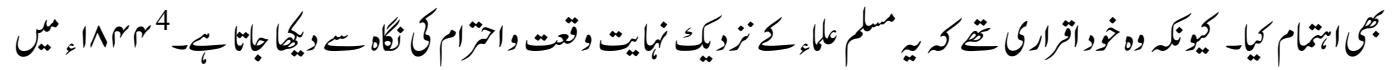

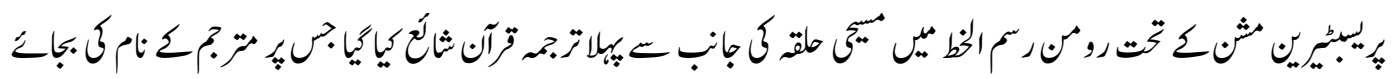

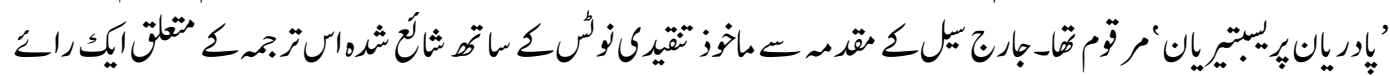

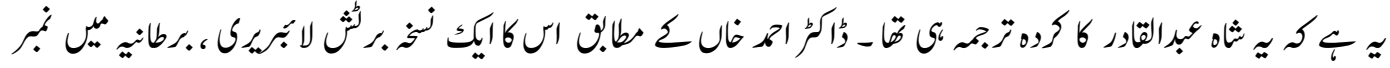

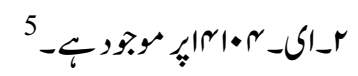

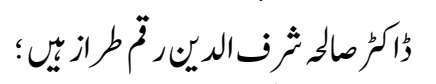

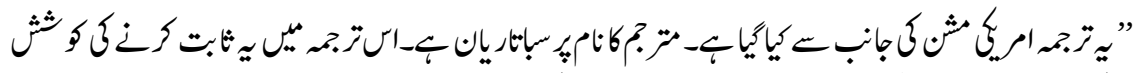

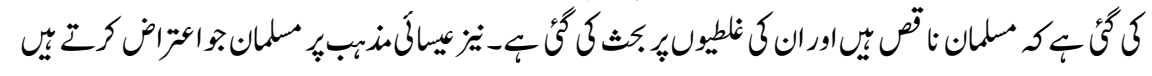

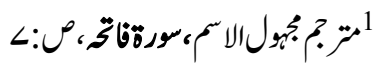
L 10

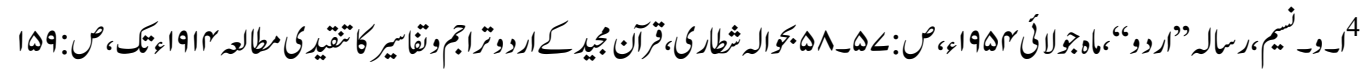

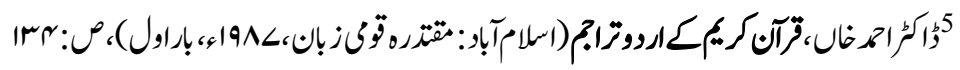




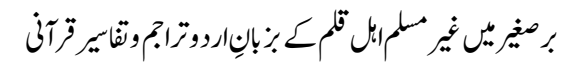

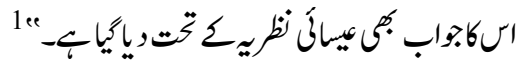

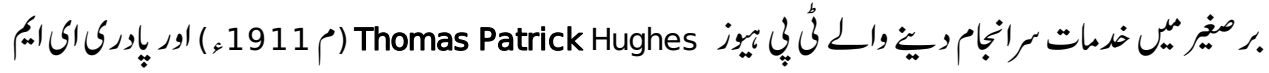

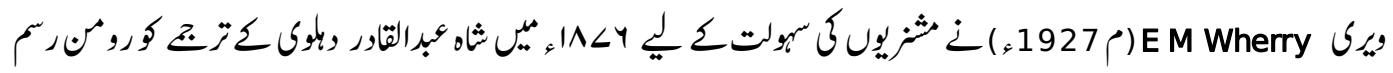

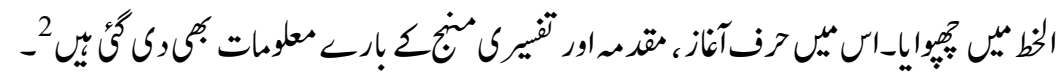

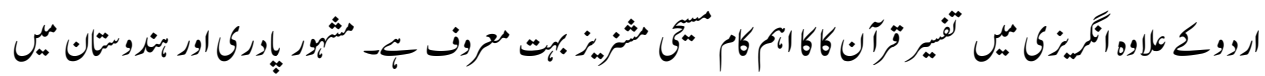

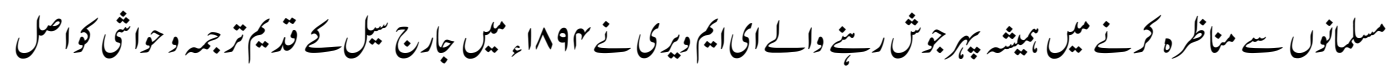

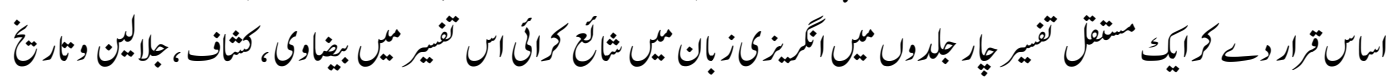

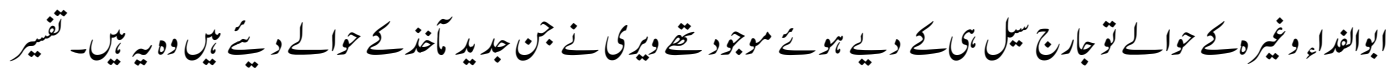

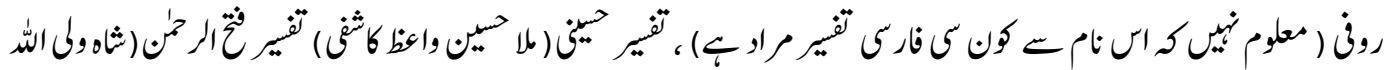

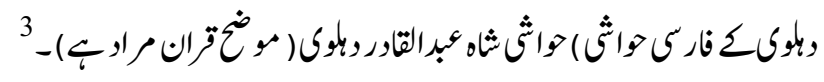

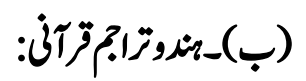

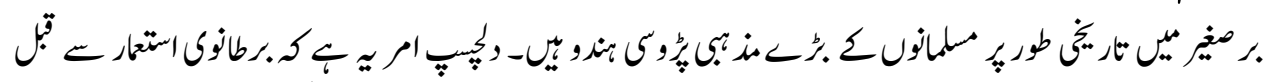

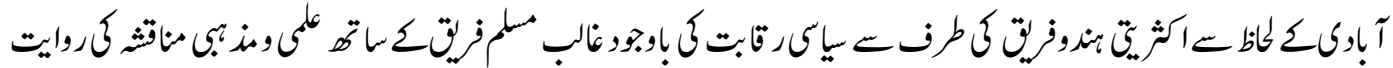

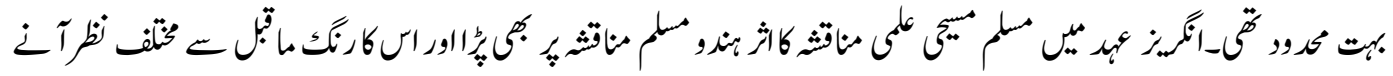

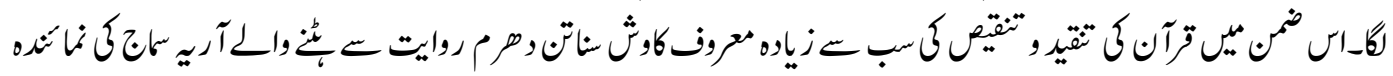

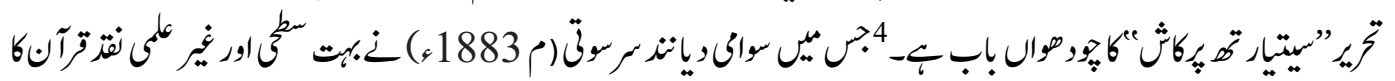

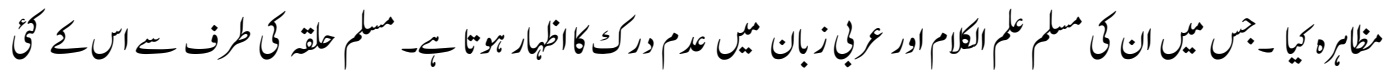
- 5 ¿

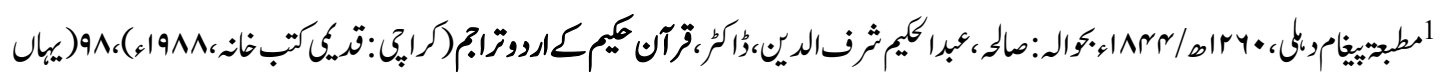

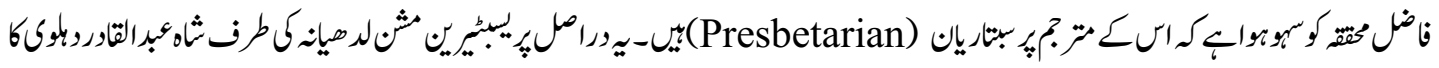

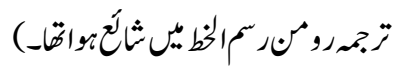

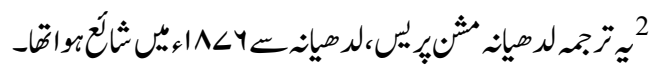
3

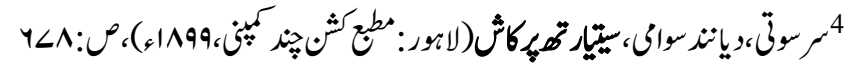

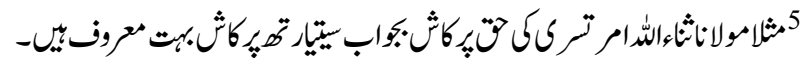




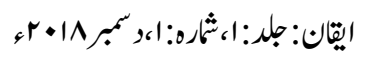

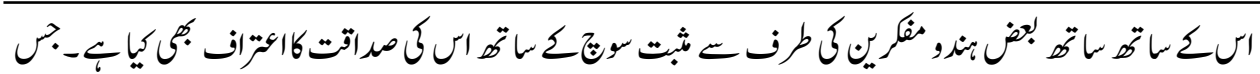

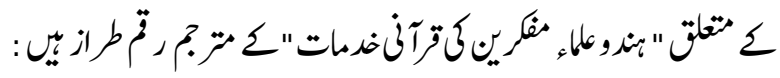

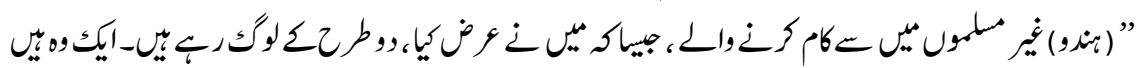

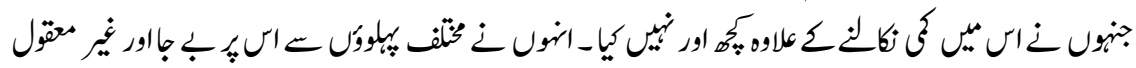

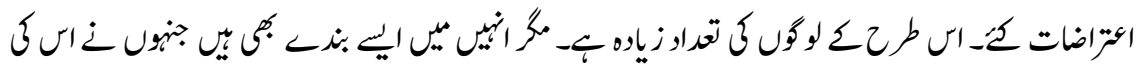

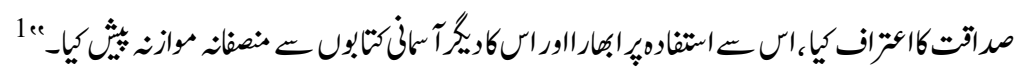

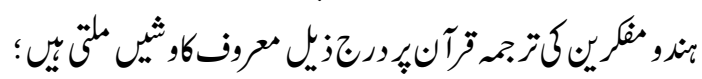

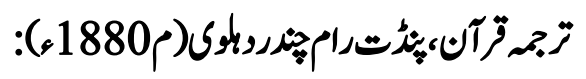
مطع مجمول، 1943

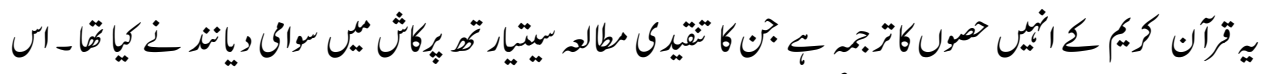

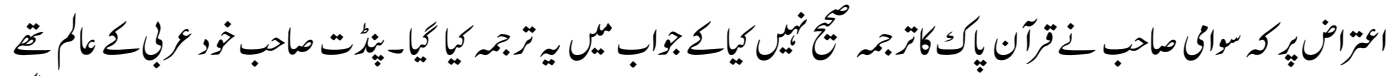

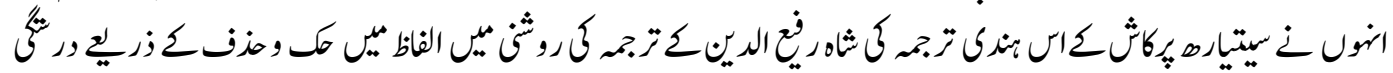

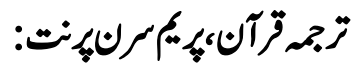

آ

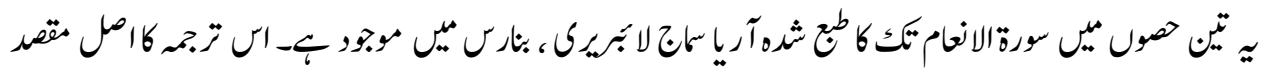

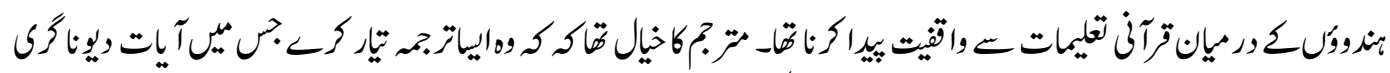

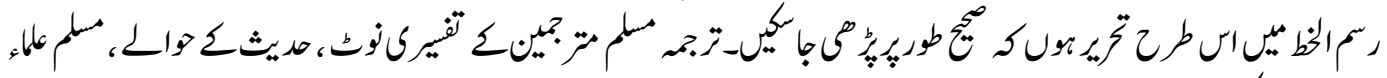

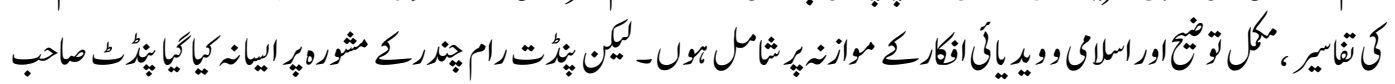

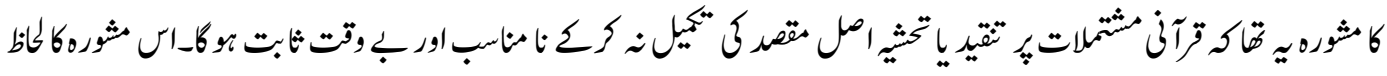

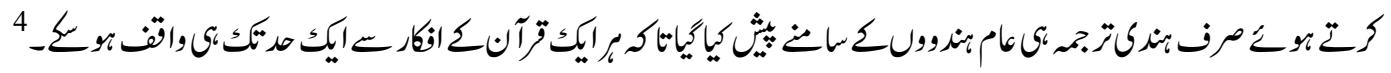

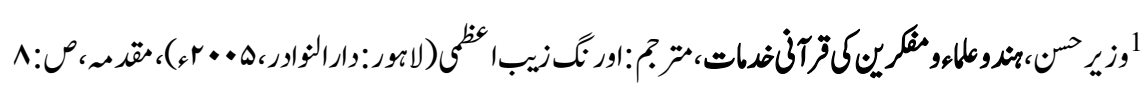

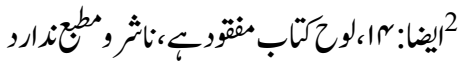

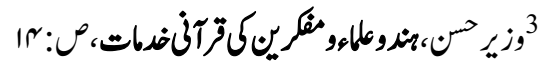

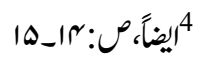




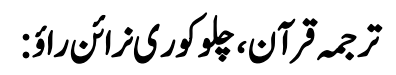

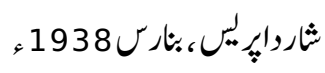

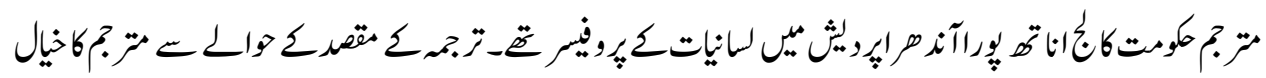

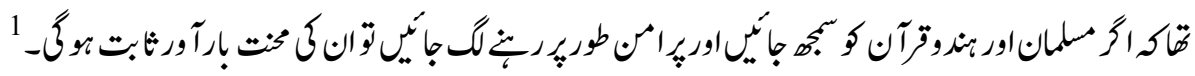

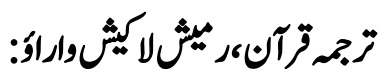

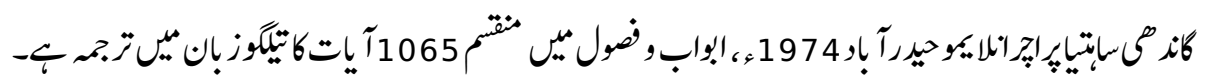

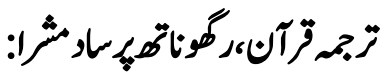

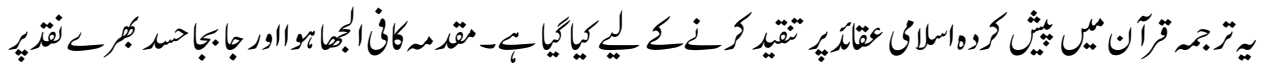

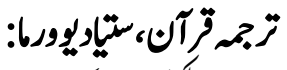

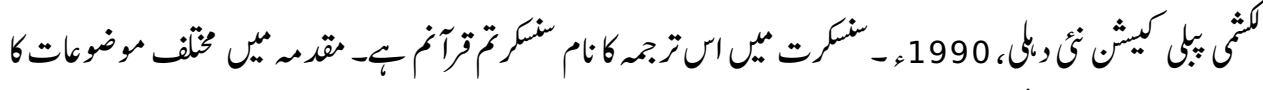

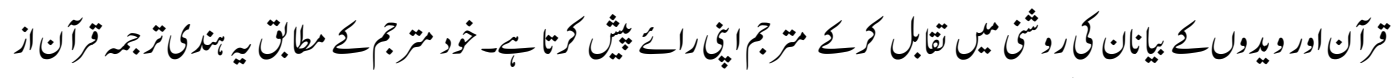

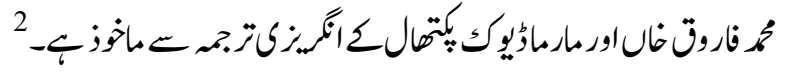

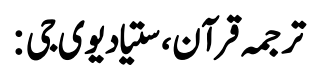

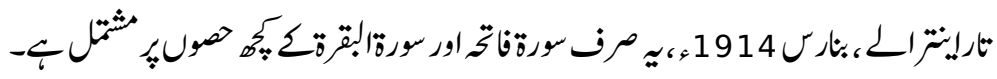

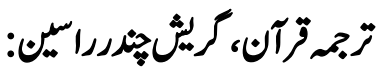

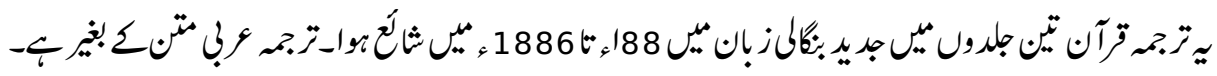

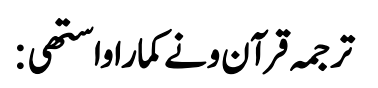

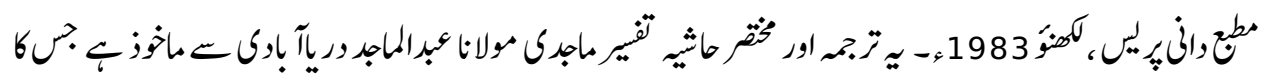

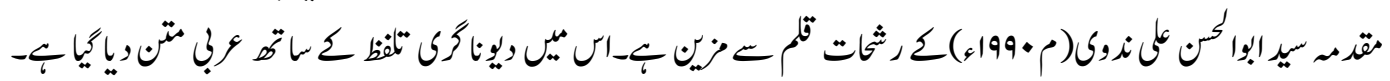

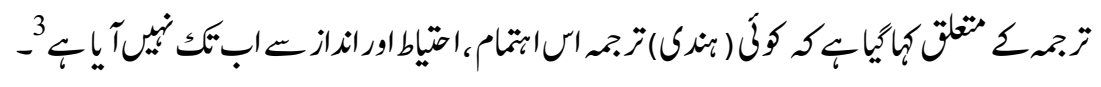

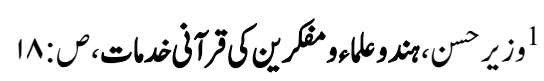

19:14:

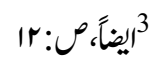




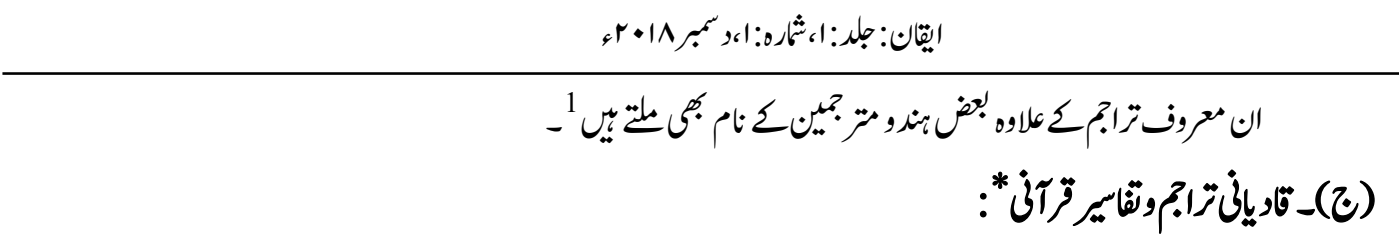

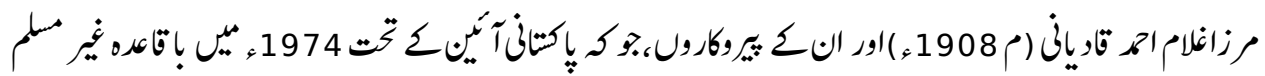

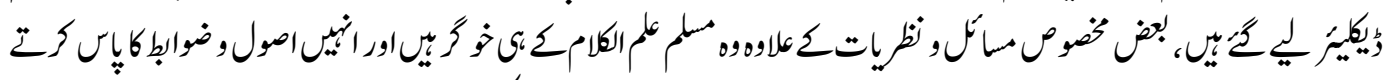

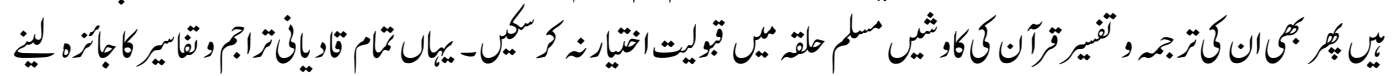

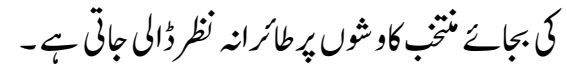

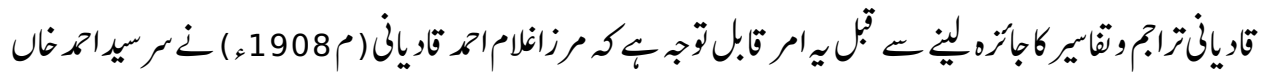

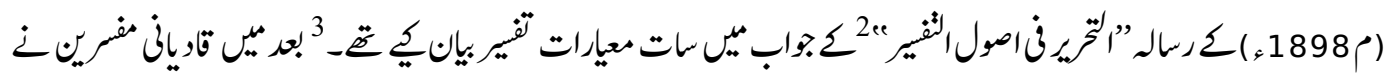

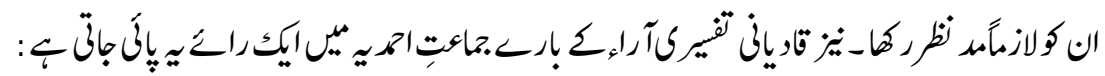

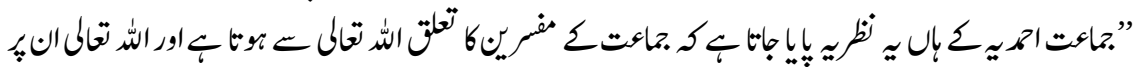

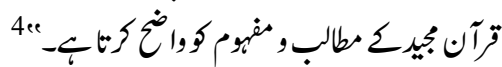

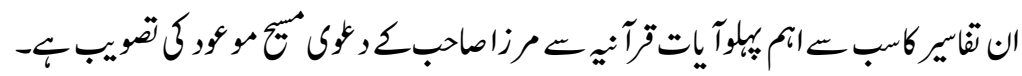
تفيربان مورهم زاغلاماحم قاريأن:

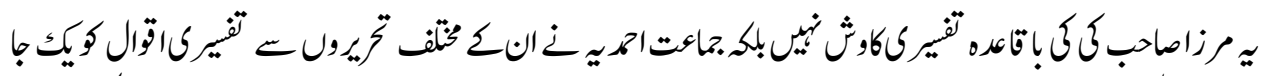

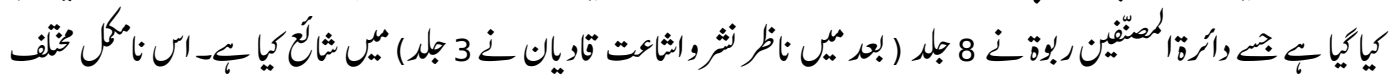

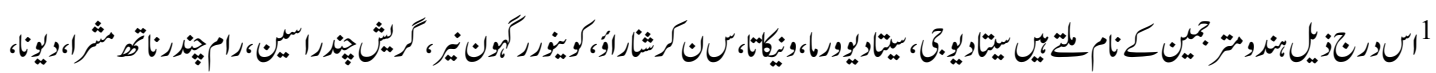

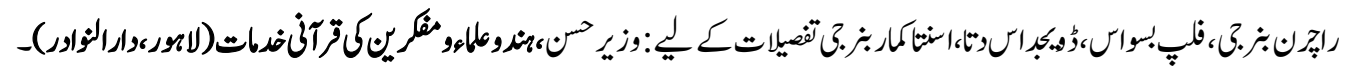

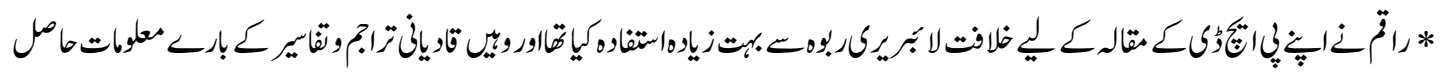

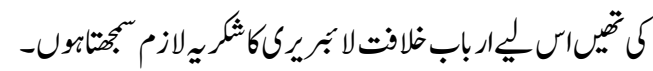

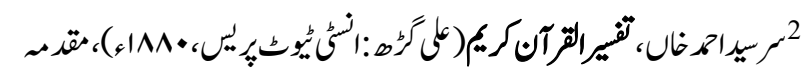

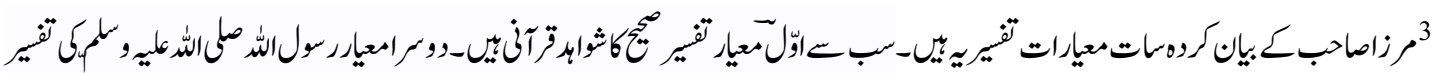

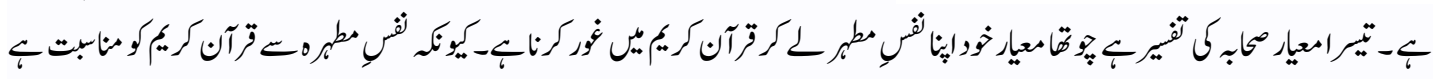

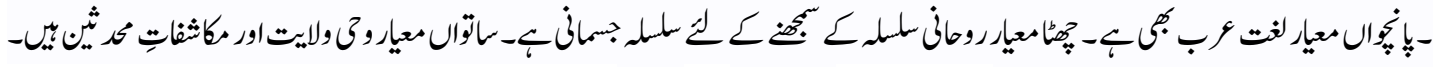

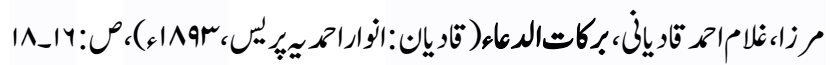

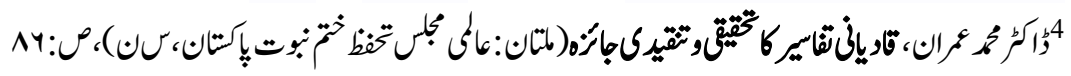




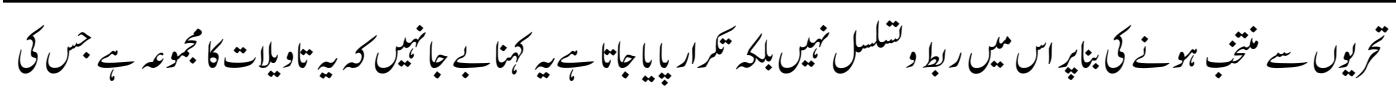

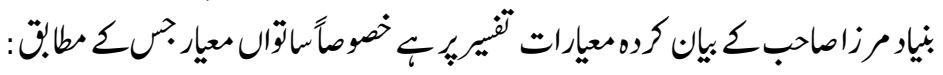

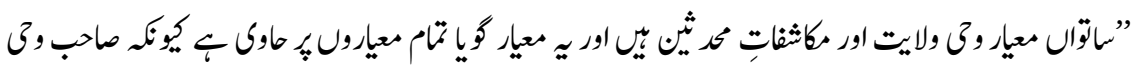

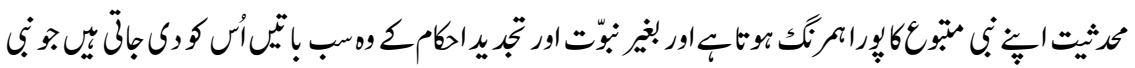
كوركاباتي يت

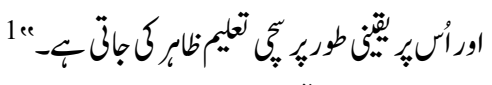

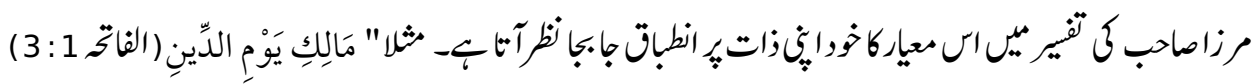

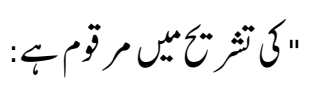

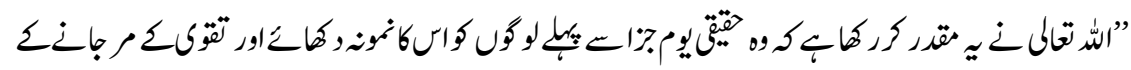

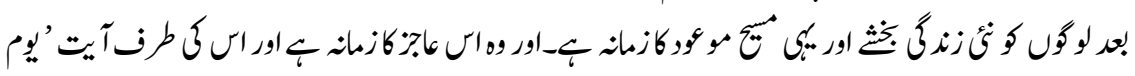

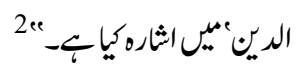

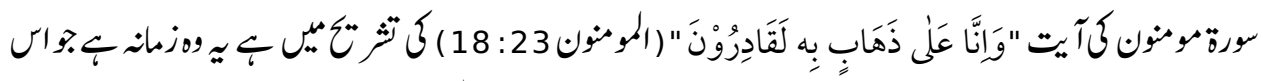

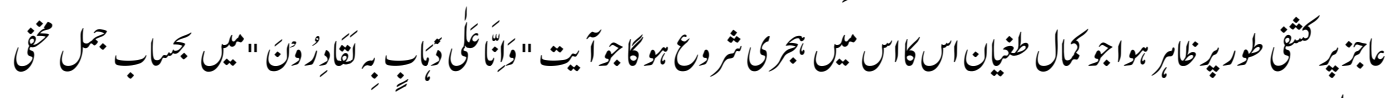

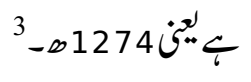

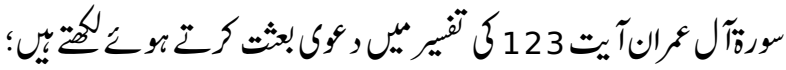

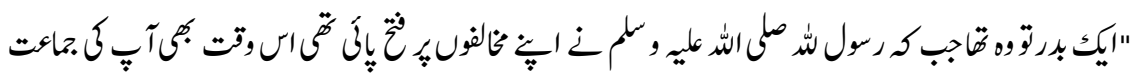

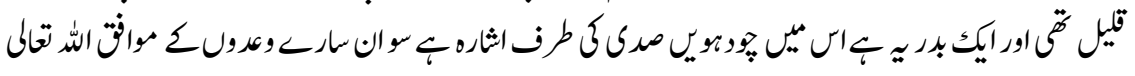

$$
\begin{aligned}
& \text { ن }
\end{aligned}
$$

$$
\begin{aligned}
& \text { 1ايضاً، }
\end{aligned}
$$

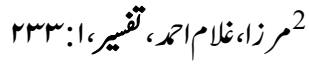

$$
\begin{aligned}
& \text { 3يضًا: ا:هام }
\end{aligned}
$$

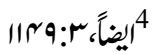




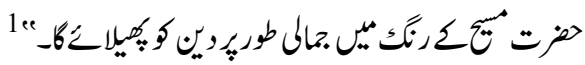

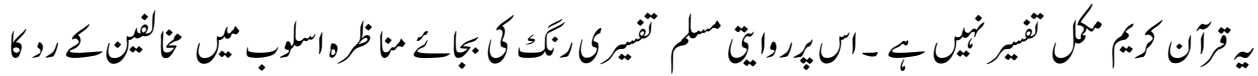

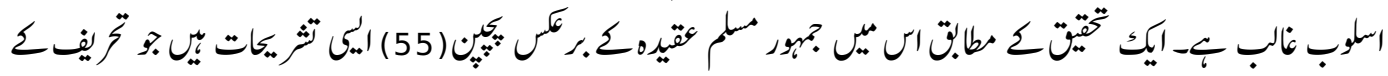

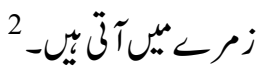

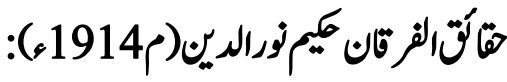

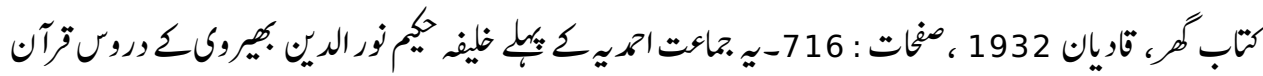

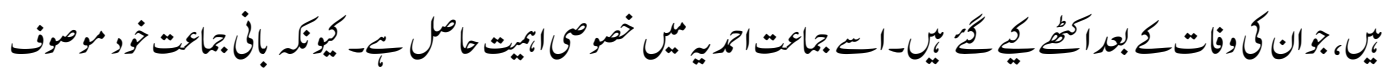

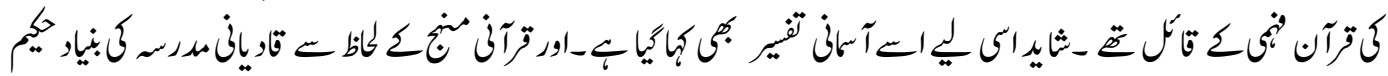

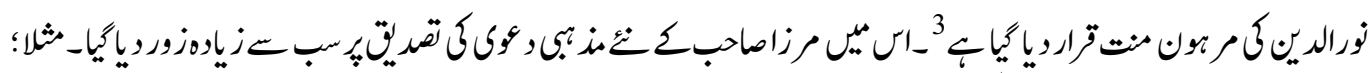

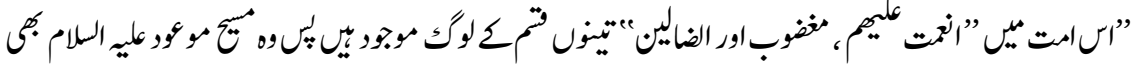

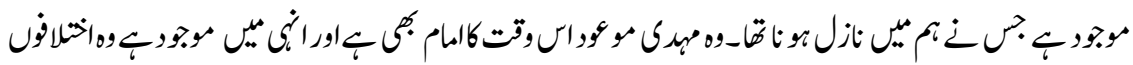

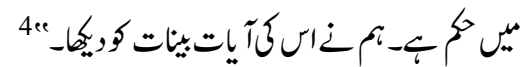

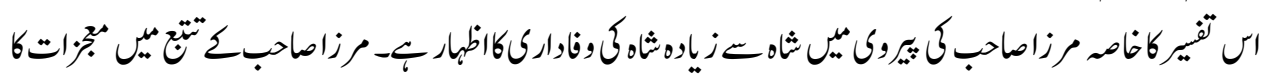

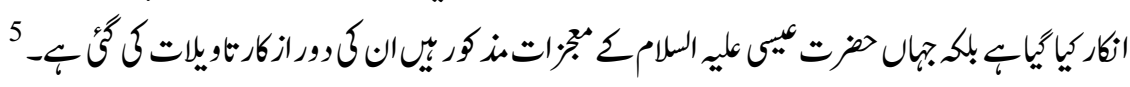

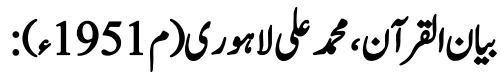

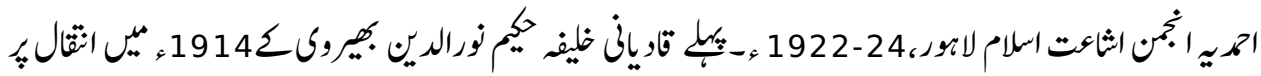

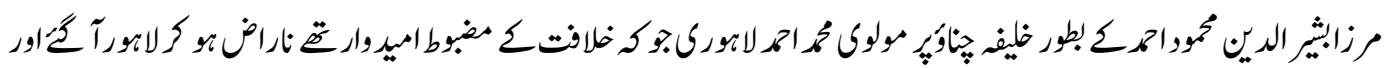

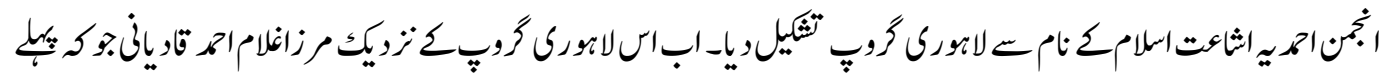

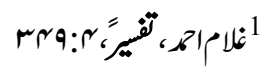

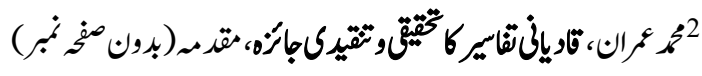

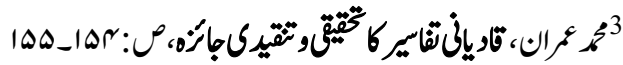

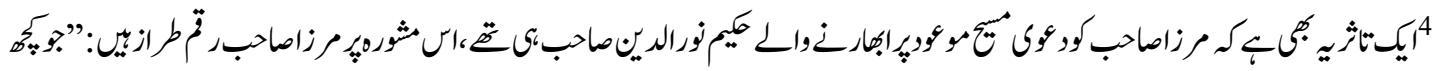

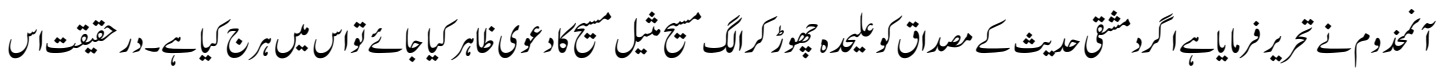

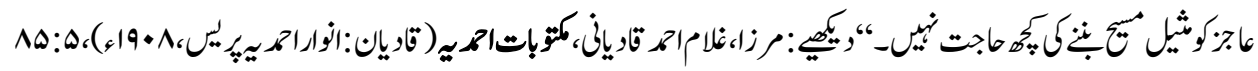

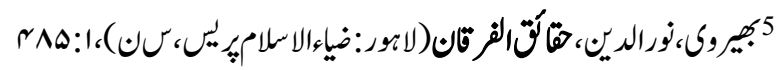




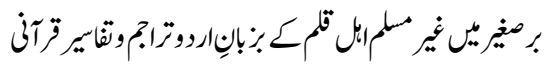

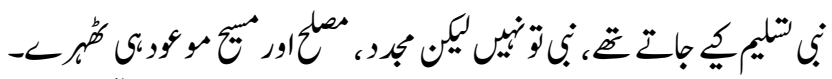

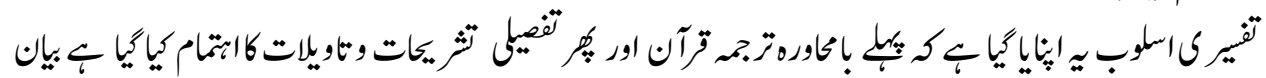

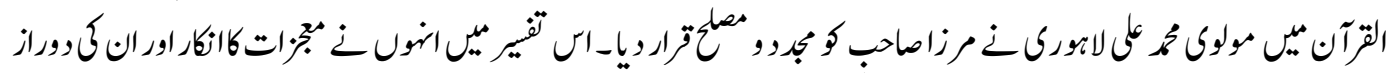

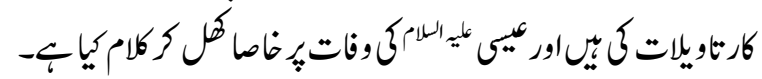

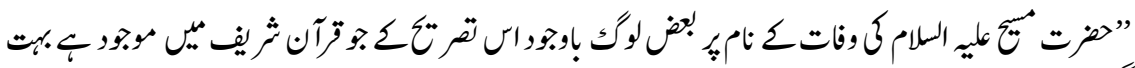

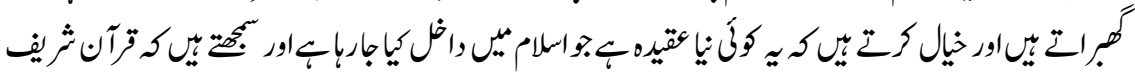

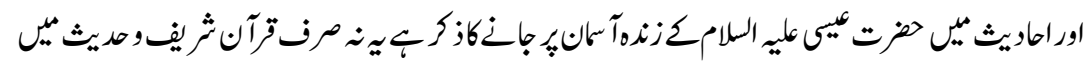

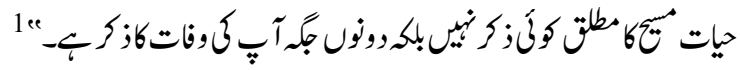

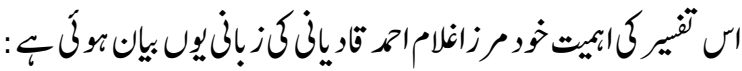

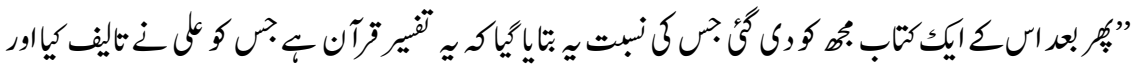

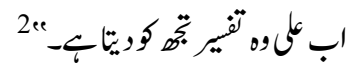
تفيركير مزابثيرالديثمحور:

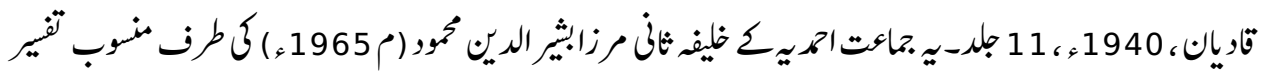

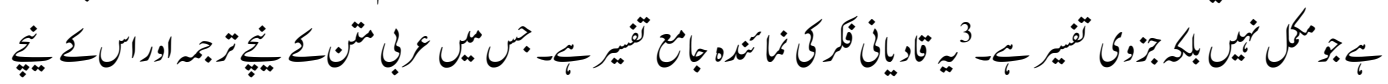

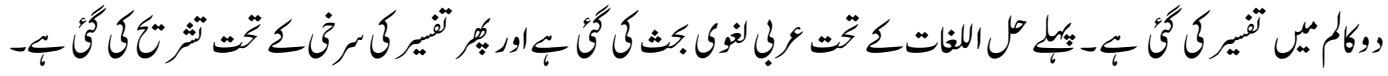

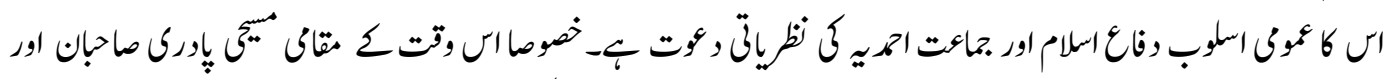

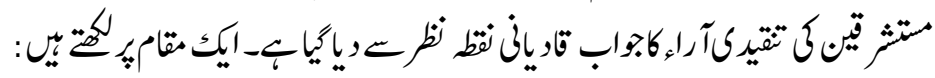

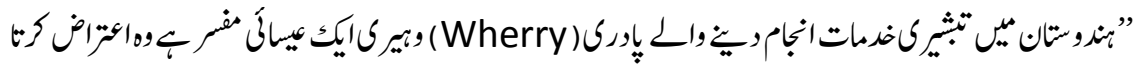

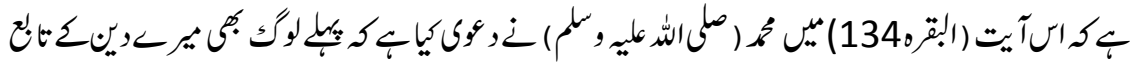
تصني

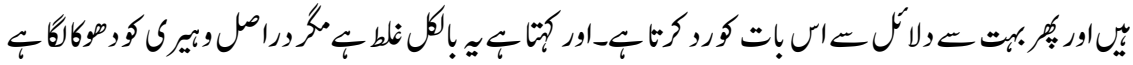

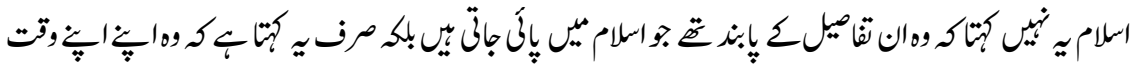

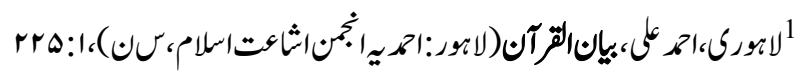
20

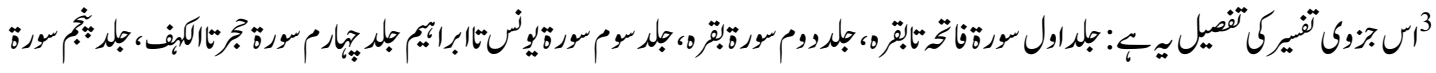

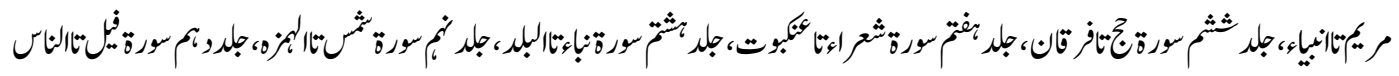




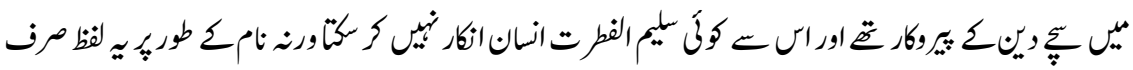

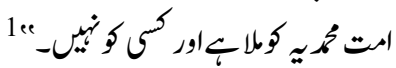

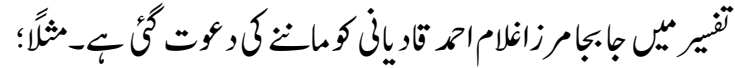

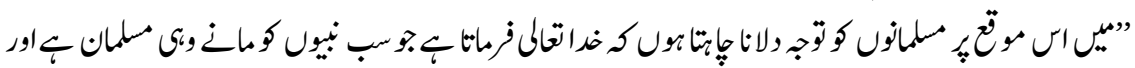

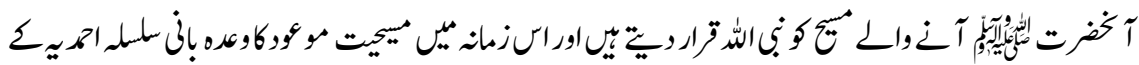

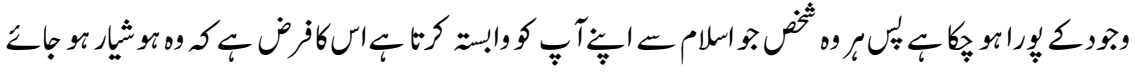

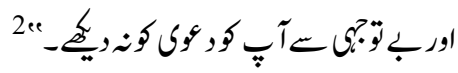

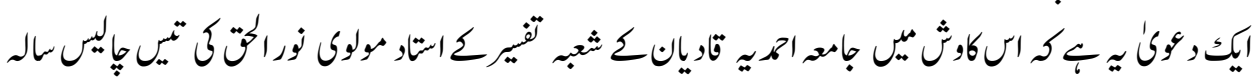

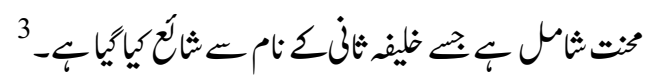

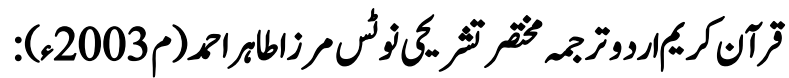

\section{Bath Press Limited Bath ,UK 2000}

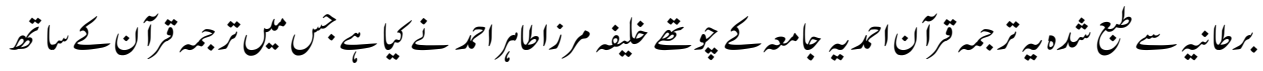

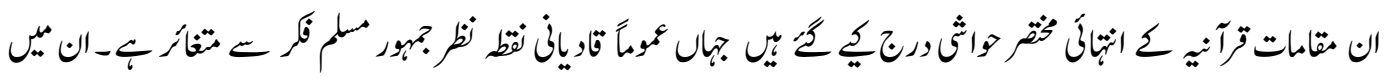

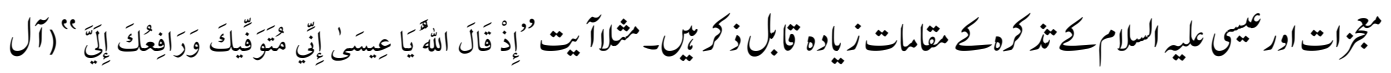

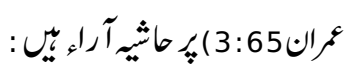

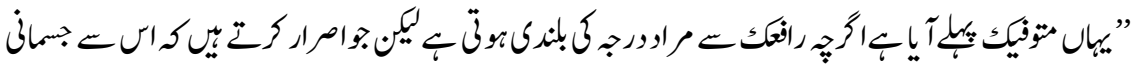

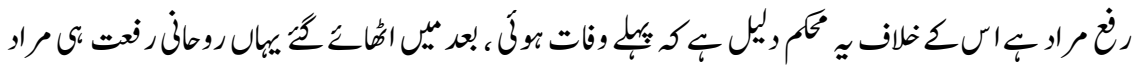

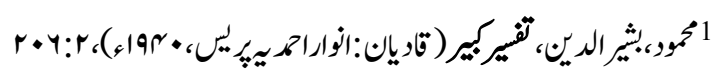

$$
\text { 2 }
$$

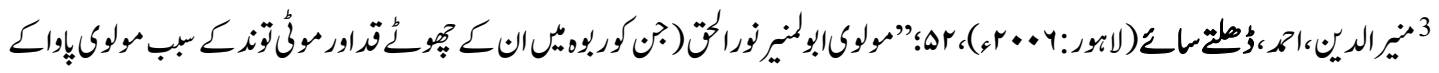

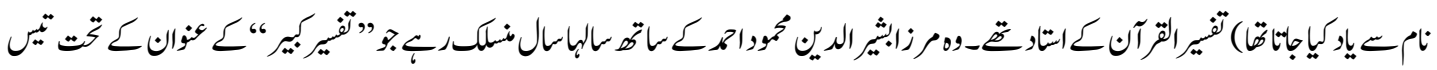

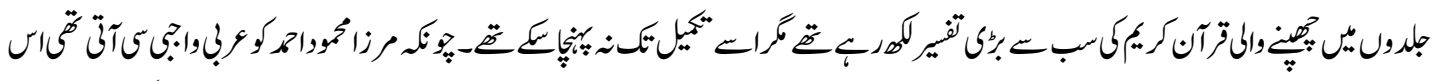

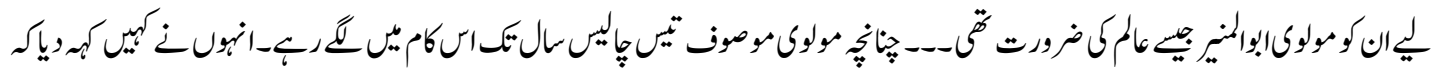

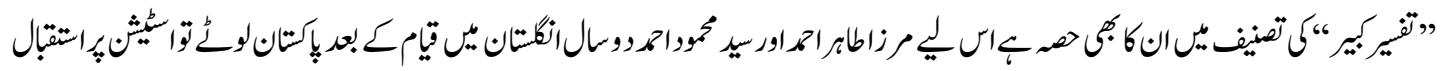

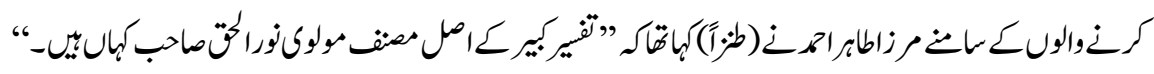




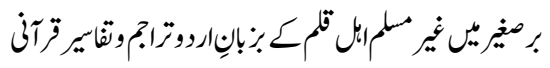

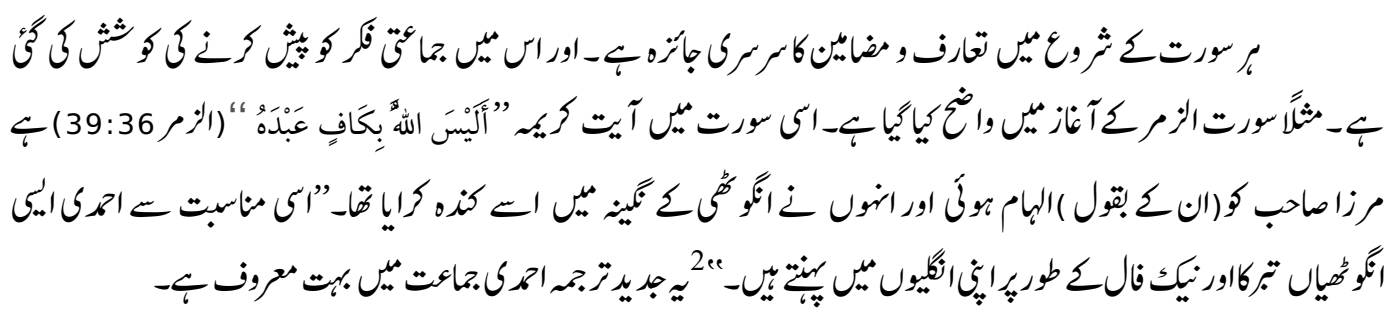
:The Holy Quran By Moulavi Sher Ali (1947)

\begin{abstract}
قايان،

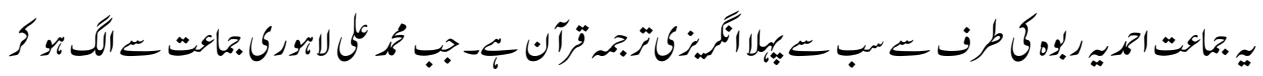

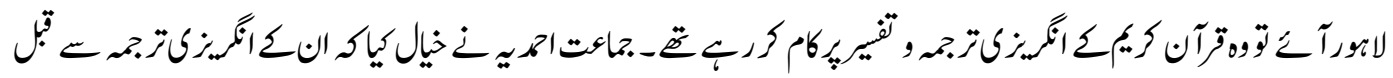

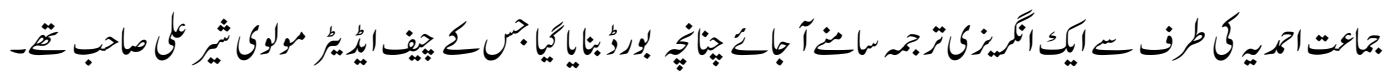

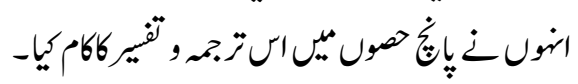

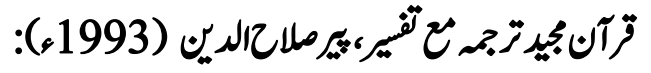

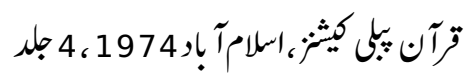

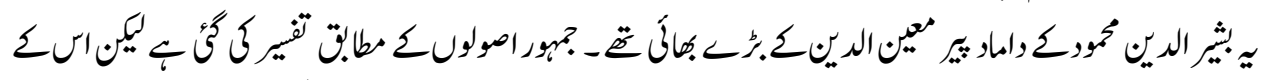

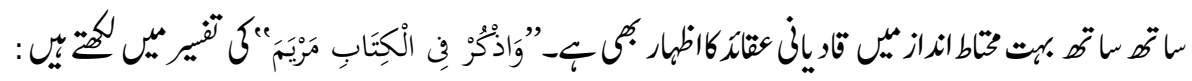

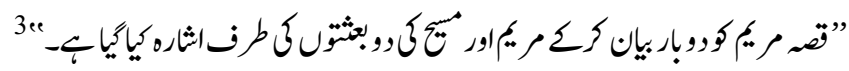

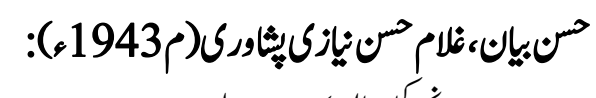

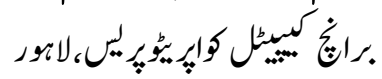

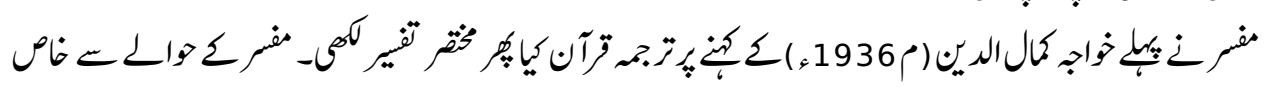

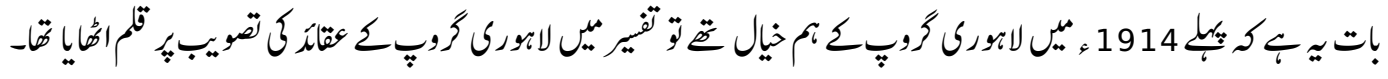

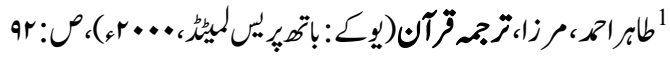

$$
\begin{aligned}
& \text { N }
\end{aligned}
$$

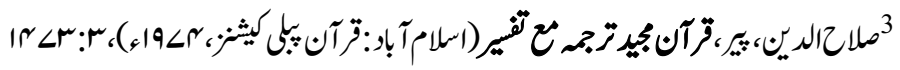




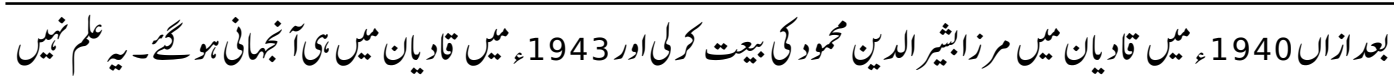

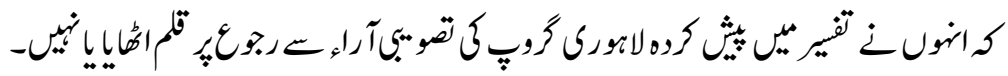

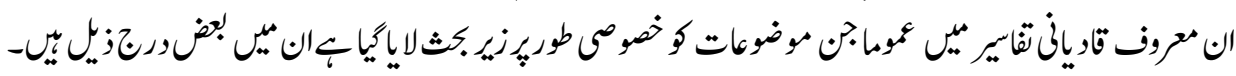

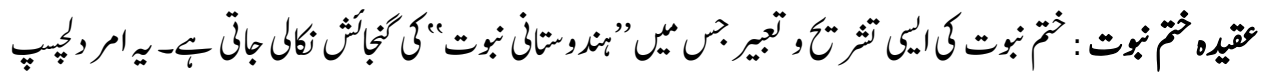

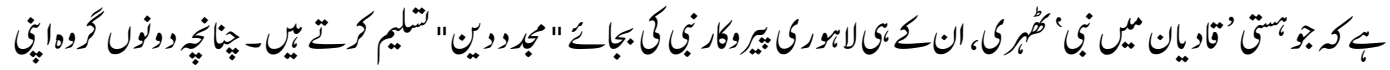

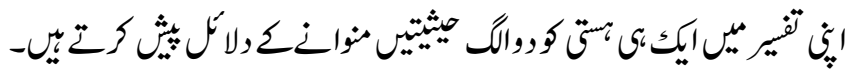

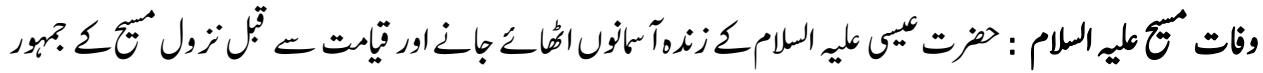

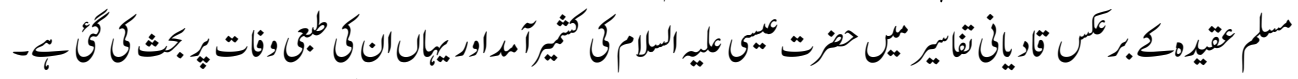

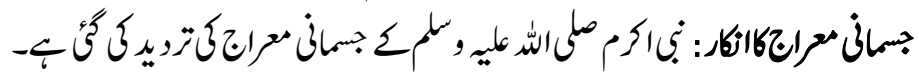

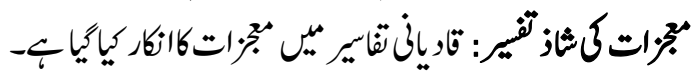

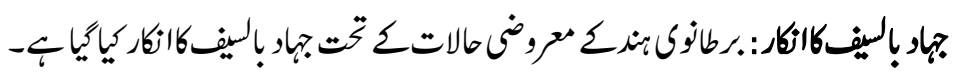

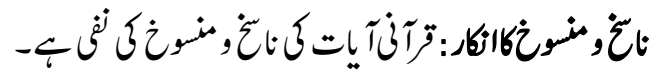

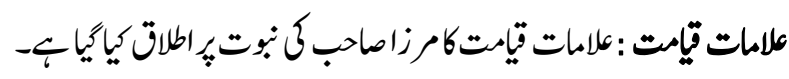

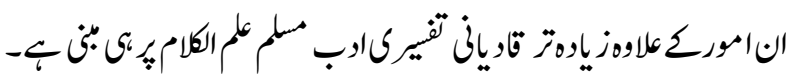

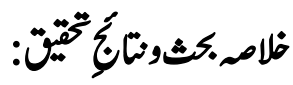

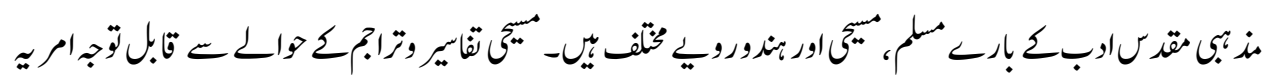

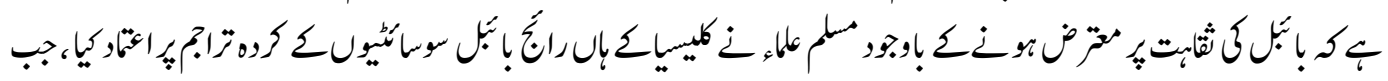

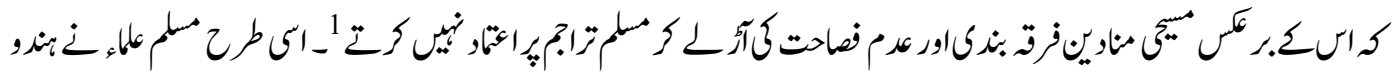

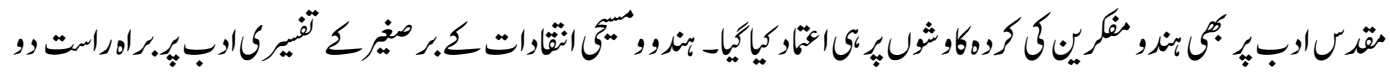
م

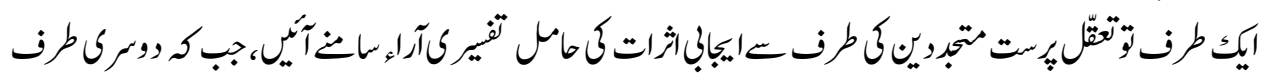

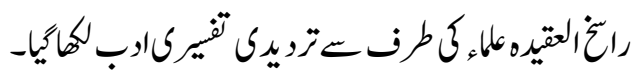

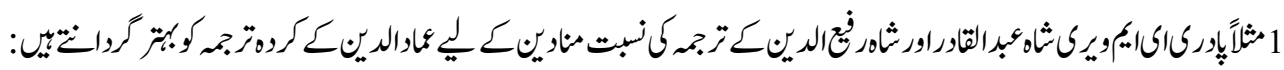
Wherry,E. M, The Muslim Controversy, (London: Christian Literature Society, 1905), p:vi ( Preface) 


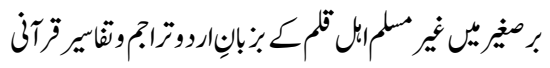

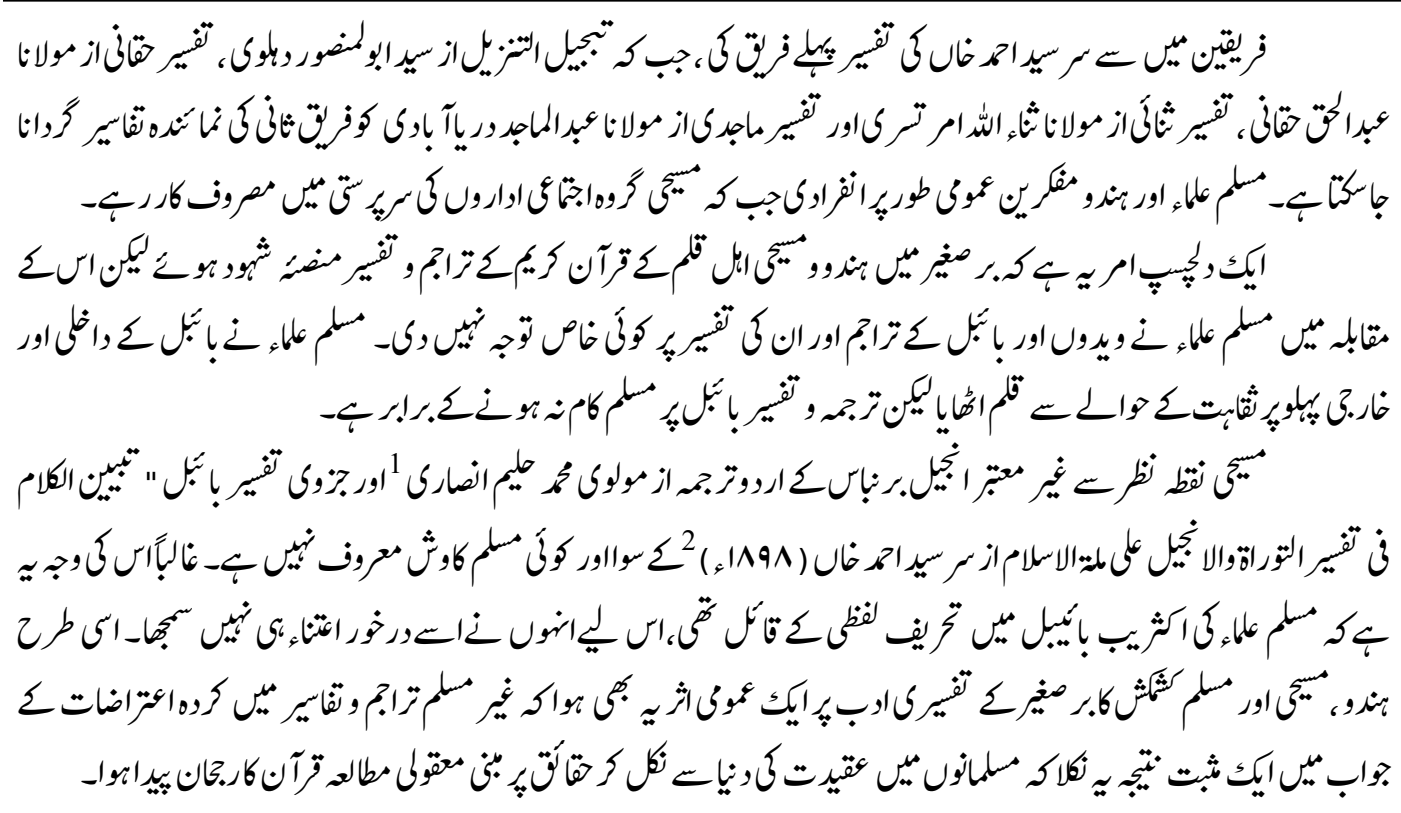

(c) (i) This work is licensed under a

Creative Commons Attribution 4.0 International License.

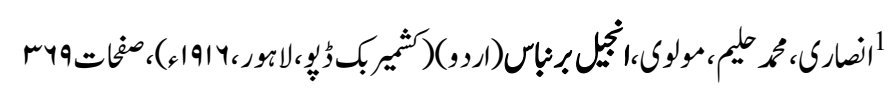

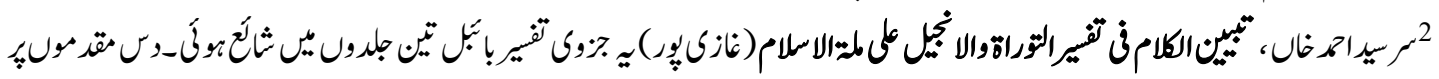

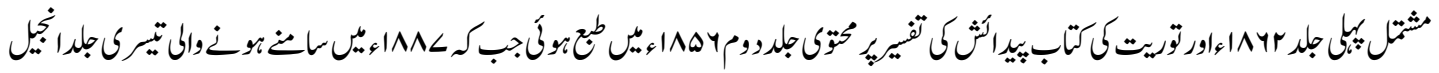

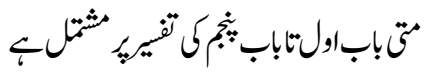

